\title{
Siluetas Femeninas en Medios de Comunicación: Estéticas para la Subjetivación ${ }^{*}$
}

\author{
María-Alejandra Energici \\ Académica de la Facultad de Psicología de la Universidad Alberto Hurtado (UAH). Santiago, Chile. \\ E-mail: menergic@uahurtado.cl.
}

\section{EL VOLUMEN DEL CUERPO EN LA SOCIOLOGÍA: LA FOCALIZACIÓN EN LA CORPORALIDAD GORDA}

$\mathrm{E}^{1}$ estudio del cuerpo en sociología ha sido un asunto más bien de interés reciente (Le Breton, 2002; Shilling, 2012). El foco de las investigaciones sobre el volumen corporal se ha focalizado en un tipo de silueta o volumen corporal: la gordura. Los fat studies (Brochu y Esses, 2011; Rothblum, 2011; Solovayy Rothblum, 2009; Wann, 2009), la investigación sobre la corpulencia (Giacoman, 2010) o los estudios críticos sobre gordura (Smailes, 2014) son un campo disciplinar incipiente, sobre todo en el mundo de habla hispana. Si bien el movimiento social de los fat studies data de la década de 1970, su institucionalización como campo académico es reciente (por ejemplo, en el 2012 se fundó la revista Fat Studies) y su desarrollo se ha radicado en los países anglosajones. En español aún no contamos con una traducción aceptada para este tipo de investigaciones.

En los últimos años se ha generado una extensa evidencia sobre la discriminación que sufren las personas gordas en todos los ámbitos de su vida, desde aquellos aspectos más institucionales, como el trabajo y la educación (Mason, 2012; O'Brien, Latner, Ebneter y Hunter, 2013; Sobal, 2011), a cuestiones más personales como las posibilidades de emparejarse (Aitsi-Selmi, Bell, Shipley y Marmot, 2014; Kark y Karnehed, 2012; Lupton, 2013; Mason, 2012) o los sentimientos de desagrado (Vartanian y Smyth, 2013) que producen en los demás. La estigmatización tiene una serie de efectos en la vida cotidiana de las personas

*Este trabajo es parte del proyecto financiado por el Fondo de Desarrollo Científico y Tecnológico (FONDECYT) \#11170317: El cuerpo en lo social. 
obesas, se ha documentado que evitan la consulta médica (Sobal, 2011), el transporte público (Colls y Evans, 2014) y tienen más posibilidades de ser violentados físicamente, sobre todo si son mujeres (Energici, Acosta, Huaiquimilla y Borquez, 2016; Fikkan y Rothblum, 2012).

Si bien la literatura internacional ha aumentado importantemente en los últimos años (Fikkan y Rothblum, 2012), los datos que tenemos en Latinoamérica y Chile son escasos. Erika Collipal y su equipo (2006, 2015) han publicado dos investigaciones en esta línea. La primera, realizada con 372 adolescentes entre 14 y 16 años de la ciudad de Temuco (CLP), concluyó que el concepto de obesidad se asocia con gordura, grasa, discriminación, depresión, enfermedad, ansiedad, problemas, baja autoestima, chatarra y sedentarismo, por nombrar algunos (Collipal, Silva, Vargas y Martínez, 2006). Estos resultados fueron replicados en un estudio posterior con 200 jóvenes de entre 18 y 20 años de la misma ciudad, obteniendo resultados similares (Collipal y Godoy, 2015). Por otra parte, Energici y su equipo al. (2018; 2017; 2016) realizaron una investigación con grupos de discusión en los que participaron 49 hombres y mujeres de la ciudad de Santiago de Chile. Entre los hallazgos se relata violencia, discriminación y bullying hacia las personas gordas, identificándose principalmente dos formas: una directa a través del insulto y otra más indirecta, desde la cual se exige la invisibilización del cuerpo gordo.

En Brasil, algunas investigaciones han documentado discursos gordofóbicos que incitan a la violencia y la discriminación en usuarios de Internet (Riscado, 2019; Silva Araújo, de Lima Coutinho, Pereira Alberto, Dias Santos y de Lima Pinto, 2013). De manera similar al caso chileno, es una forma de prejuicio legitimada socialmente. En la evaluación de un programa en la perspectiva de Health at Every Size (Salud en Todos los Tamaños) en el que participaron 14 individuos, estos declararon que la gordura tenía un impacto en ciertos aspectos de su personalidad, reduciendo las posibilidades de vínculos e interacciones sociales. Los participantes también reportaron haber sufrido bullying y discriminación por el tamaño de sus cuerpos (Ulian, Gualano, Benatti, de Campo-Ferraz, Roble, Modesto, Unsain, De M. Sato, Machado Poppe y Scagliusi, 2016). Estos trabajos, si bien acotados, permiten anticipar que el caso latinoamericano no es una excepción respecto de la discriminación que sufre el cuerpo gordo. 
Dadas las tasas de prevalencia de obesidad y sobrepeso en los países desarrollados y en vías de serlo, no sorprende este énfasis en el cuerpo engrosado, sin embargo, en términos generales, este tipo de investigaciones asumen que el cuerpo delgado es un ideal social, sin indagar en dicho supuesto. En otras palabras, el cuerpo delgado opera como un referente no indagado en las ciencias sociales. En este sentido, la delgadez (considerada académicamente como el antónimo de la gordura) no se ha problematizado teóricamente y se tiende a aceptar como una condición deseable y atractiva (Cundall y Guo, 2017). La investigación en esta área se ha dedicado esencialmente a cuestionar el efecto que tiene la excesiva internalización del ideal de la delgadez sobre la imagen corporal, esto tanto en estudios feministas (Fikkan y Rothblum, 2012), como en indagaciones más clínicas que buscan identificar factores predictores de trastornos alimenticios ${ }^{1}$. En otras palabras, se considera que "la anorexia (auto-inanición) y la bulimia (atracón e inducción del vómito) son formas extremas de perder peso para ajustarse a los estándares culturales de belleza occidental y para mantener control sobre el propio cuerpo" (Lorber y Martin, 2013: 15)2.

\section{LA ESCASEZ DE MODELOS EXPLICATIVOS}

Como consecuencia de la producción académica, sabemos que los diversos volúmenes o siluetas corporales se valoran de manera diferente: la gordura es ampliamente rechazada y discriminada, mientras que la delgadez se idealiza y desea socialmente (Bair, Steele y Mills, 2014; Veldhuis, te Poel, Pepping Konijn y Spekman, 2017). Generalmente, la investigación académica se ha concentrado en medir, de distintas formas y en diversos ámbitos, el rechazo hacia la gordura, asumiéndose que, por contraposición, la delgadez es positiva, deseable y atractiva. La deseabilidad de la delgadez es un asunto más presupuesto que estudiado.

Por otra parte, esta apreciación sobre el rechazo de la gordura, ha estado escasamente acompañada de teorías o modelos explicativos, es decir, la investigación sobre la discriminación y el prejuicio hacia la gordura ha sido criticada por ser excesivamente descriptiva, observándose y documentándose la ocurrencia de la exclusión, sin ofrecerse una explicación (O'Brien, Lather, Ebneter y Hunter, 2013). En este sentido, en términos generales, no se ha profundizado en los significados que se asocian al cuerpo gordo para constituirlo como una condición rechazable socialmente, ni los sentidos que se atribuyen al cuerpo 
delgado para construirlo como el objeto de deseo y atractivo social. Esto es especialmente cierto para la delgadez, pues si bien se encuentran algunos estudios comprensivos y críticos sobre gordura (Energici, 2018; Fraser, Maher y Wright, 2010; Halse, 2009; Harwood, 2009; Jutel, 2009; Tischner, 2013; Wright, 2009; Wright y Harwood, 2009), como mencioné anteriormente, los sentidos con los que se construye la delgadez, del mismo modo que su valoración, son un asunto más implicado que indagado.

Los estudios críticos sobre gordura, muestran que esta se asocia a un grupo de acciones típicas de cuidado que no implican únicamente la vigilancia de la alimentación y el ejercicio, sino también destrezas morales de control, disciplina y moderación, entre otras (Energici, Acosta, Huaiquimilla, y Borquez, 2016; Energici, Acosta, Borquez y Huaiquimilla, 2017;; Halse, 2009; Jutel, 2009; Tischner, 2013; Wright, 2009). Y, por contraposición, se presupone que la delgadez es el logro constante y exitoso de dichas acciones.

\section{El giro afectivo}

Propongo que, en parte, la ausencia de modelos explicativos se debe a la aproximación teórico-metodológica con la que se ha estudiado el cuerpo, por lo que: "En un nivel fundamental, los métodos [tradicionales] dependen de la creación de alguna forma de texto, capturado a través de la grabación de voces y observaciones, que puedan ser analizados discursivamente" (Renold y Mellor, 2013: 23). Ello es particularmente complejo para las investigaciones que buscan indagar sobre asuntos corporales o corporalizados, como lo son la gordura y la delgadez. En este contexto, el giro afectivo, o el interés por indagar en la afectividad, ha emergido en los últimos treinta años justamente por las dificultades antes mencionadas (Coleman, 2013).

Desde 1995 han prevalecido dos nociones o aproximaciones hacia los afectos:

1. De adentro hacia afuera (inside-out). Esta corresponde a la teorización tradicional de los afectos; estos son localizados 'dentro' del cuerpo y "pueden ser identificados como respuestas y reacciones discretas a influencias 'externas'"'4 (Coleman, 2013:31). Desde esta 
perspectiva el cuerpo se considera como universal y se trazan procesos que van desde lo biológico hacia lo sociocultural, donde el primero es determinante.

2. De afuera hacia adentro (outside-in). Descansa principalmente en la tradición deleuziana, en la cual Brian Massumi es uno de sus principales exponentes. En esta aproximación el afecto es relacional y constitutivo:

Esto es, en contraste con el modelo de afecto de adentro hacia afuera, donde el afecto es innato y luego da forma a las relaciones entre diferentes cuerpos y sujetos, esta forma de dar cuenta deleuziana del afecto argumenta que es a través de relaciones afectivas entre cosas, que estas cosas toman forma, o que estas cosas llegan a ser/siendo ${ }^{5}$ (Coleman, 2013: 32).

Si bien no existe consenso respecto de la noción de afecto entre los autores del giro afectivo (Coleman y Ringrose, 2013), lo que esta perspectiva abre es la posibilidad de considerar teórica y metodológicamente aquellas 'experiencias insignificantes' (Hickey-Moody, 2013). De ahí que se puedan privilegiar asuntos u objetos de estudios que no son tan aprehensibles desde la palabra como los cuerpos y sus estéticas:

Como una idea confusa, el afecto es lo que nos mueve. Es una corazonada. Un consejo visceral. El afecto es un punto de partida desde el cual podemos desarrollar métodos que sean conscientes de la política de las estéticas: métodos que respondan con sensibilidad a las influencias estéticas en las emociones humanas y el modo en que cambian las capacidades corporales. (Hickey-Moody, 2013:. 79).

Estudiar los afectos nos permite comprender el impacto que tienen las estéticas cotidianas en nuestras subjetividades (Hickey-Moody, 2013). Para efectos de este trabajo, indagar en los afectos de imágenes cotidianas, como son las imágenes de publicidad o revistas, nos permite comprender o articular asuntos que hasta el momento han sido omitidos o subvalorados en los análisis sobre diversas formas corporales ${ }^{6}$. 
Por último, si consideramos que los afectos movilizan y que nos direccionan hacia ciertos objetos, sujetos o relaciones son, por tanto, políticos (Ahmed, 2007, 2017). Dicho de otro modo, integrar lo afectivo en el análisis de imágenes permite aprehender teóricamente su potencial poder y su capacidad de incidir en el cuerpo y sus relaciones (Coleman, 2013).

\section{NOTAS TEÓRICAS Y CONTEXTUALES A CONSIDERAR PARA EL DISEÑO METODOLÓGICO}

En este contexto, realizamos una investigación con el objetivo de analizar los significados, valoraciones y acciones típicas que se asocian a distintas siluetas corporales. El objetivo del estudio, si bien implica comenzar por la identificación de diversas formas de cuerpo, se concentra en las relaciones de las que éstas participan, de modo de comprender lo que se articula en la gordura, delgadez $u$ otras formas corporales. Por lo tanto, este es un estudio exploratorio que busca contribuir a la generación de modelos más comprensivos sobre el rechazo de la gordura y, así también, entender el modo en que funciona la (supuesta) deseabilidad de la delgadez.

Para esto, hemos decidido trabajar con imágenes de medios de comunicación, pues estas son centrales en la instalación de ideales culturales las sociedades contemporáneas (Coleman, 2013). Existen diversas investigaciones sobre los estereotipos de género principalmente a través de análisis de frecuencia y correlaciones de diversas variables (Bonavitta y Garay Hernández, 2017; García-Muñoz y Martínez-García, 2009; Gómez-Escalonilla, García, Santín, Rodríguez y Torregrosa, 2008; Mart, 2009; Uribe, Manzur, Hidalgo y Fernández, 2008). Esto estudios, si bien dan cuenta de la presencia o ausencia de ciertos tipos de cuerpo en los medios, sobre todo en términos de sexo y actividades asociadas, no hacen referencia al tamaño corporal y, más importante aún, no permiten dar cuenta de manera comprensiva a los tipos de cuerpos que encontramos en los medios de comunicación.

Dado el foco comprensivo de esta empresa, a diferencia de los estudios cuantitativos, buscamos trabajar con un grupo pequeño de imágenes. Para indagar cualitativamente el material visual, desarrollamos una ruta analítica intensiva que toma de los análisis del discurso de Ian Parker (1996) el trabajo minucioso y detallado sobre distintos aspectos de la imagen. 


\section{Metodología}

Los resultados que presentamos a continuación corresponden al primer objetivo específico del proyecto en curso "El cuerpo en lo social: experiencias corporales reflexivas en torno a la gestión cotidiana del peso corporal en adultos de la ciudad de Santiago de Chile"7. La recolección se ha realizado en dos fases: la primera, más amplia, buscó construir un cuerpo de imágenes robusto. Con estas imágenes se realizó un análisis cuantitativo descriptivo. Parte de este análisis se utilizó de cara a la segunda fase de la recolección: la construcción de una muestra acotada para ser analizada con estrategias cualitativas.

\section{a) Fase I. Recolección de imágenes para el proyecto de investigación}

Para la producción de datos utilizamos un criterio amplio para la recolección de imágenes: incluimos todas aquellas en las que aparecieran cuerpos o que se refiera a ellos de alguna forma (por ejemplo, a través de un objeto o texto) en revistas, publicidad en espacios públicos y en un centro comercial.

Seleccionamos revistas de alta circulación a nivel nacional. Consideramos únicamente suplementos de diarios dado que son gratuitos y cuentan con mayor circulación que las revistas que se deben adquirir por sí solas. Este proceso se realizó por un período de tres meses (31 de octubre de 2017 hasta el 23 de enero de 2018). Incluimos publicaciones que están explícitamente enfocadas a mujeres y otras que están dirigidas al público en general. Asimismo, también estimamos que fueran periódicos de distintos valores comerciales que van desde los 700 pesos chilenos (aproximadamente un dólar americano) a otros que se distribuyen gratuitamente en la vía pública. De esta manera, pudimos obtener material que está dirigido a diferentes niveles socioeconómicos.

Las imágenes, aunque fueron elegidas en las versiones impresas de las revistas, fueron recopiladas de sus versiones digitales, para contar con la mejor calidad posible. El corpus de revistas dio un total de 408 piezas que incluían artículos, publicidad y sección de modas. 
Además de lo anterior, fotografiamos publicidades en la vía pública. Para esto visitamos las estaciones del Metro con mayor flujo de Santiago de Chile: Tobalaba, La Cisterna y Universidad de Chile, ("Metro revela cuáles son las estaciones con mayor afluencia anual de pasajeros", según la encuesta realiazada en 2017) y también el centro comercial con más metros cuadrados en la misma ciudad: Mall Costanera Center ("El ranking de los malls en Chile," según la encuesta realizada en 2012). Las estaciones del Metro las visitamos el 26 de febrero de 2018 y el Mall Costanera Center al día siguiente. Del centro comercial registramos fotografías del segundo piso (donde se encuentran las tiendas que el centro comercial etiqueta como "Mujeres") y del tercero (lo mismo, pero de la categoría "Hombres e Infantil"). En total reunimos 45 fotografías.

De esta forma, en esta primera fase obtuvimos 453 piezas. Para elegir el grupo de imágenes a analizar realizamos un análisis cuantitativo preliminar de las publicidades y artículos de revista. Para efectos de este artículo, interesan aquellas piezas que nos permitan dar cuentas de diversas siluetas corporales y/o las acciones a las que se asocian. Así, clasificamos cada imagen dentro de una de las siguientes categorías:

1. Imágenes en que aparezcan siluetas o volúmenes corporales ideales (ej. piezas publicitarias de marcas de ropa);

2. Imágenes que problematicen alguna silueta o volúmenes corporales (ej. artículos sobre los efectos de la obesidad en la salud);

3. Imágenes en las que se reivindique socialmente alguna silueta o volumen corporal (ej. piezas publicitarias de marcas de ropa para mujeres gordas);

4. Imágenes en que se prescriban acciones para las siluetas problemáticas (ej. artículo de revista en que se describe una dieta);

5. Imágenes en que se presenten acciones típicas de sujetos con siluetas ideales (ej. un artículo de revista sobre la rutina de belleza de una actriz o modelo). 
La combinación de tipos de cuerpos (ideales, rechazados y reivindicados) con acciones (prescritas y típicas) tiene como objetivo dar cuenta de la red de relaciones en que se insertan los cuerpos, debido a caracterizar los significados, valoraciones y acciones típicas de cada uno.

Aquellas imágenes que no pudieron ser integradas dentro de alguna de esta categoría fueron eliminadas de esta muestra, quedando un total de 336 piezas. El análisis preliminar permitió mostrar que este conjunto presentaba una baja variabilidad en dos criterios: sexo, el $73 \%$ de las imágenes corresponden a mujeres ${ }^{8}$ y tipo de silueta, el $85 \%$ corresponde a siluetas ideales.

\section{b) Fase II. Selección de imágenes para el análisis cualitativo}

El objetivo de esta fase fue construir un corpus acotado que nos permitiera analizarlo con estrategias cualitativas. Para esto tomamos como referencias las categorías de tipos de siluetas o acciones típicas, descritas anteriormente. Así, la selección la realizamos con dos criterios:

1. Muestreo por cuotas proporcionadas, es decir, buscamos que las imágenes seleccionadas fuesen ajustadas a la cantidad de piezas clasificadas en cada categoría, al menos de manera orientativa:

2. Variabilidad dentro de la categoría. Para el caso de las categorías en que se agrupan muchas imágenes, lo que afecta particularmente a la de siluetas ideales, buscamos dar cuenta de la mayor variación posible.

En la Tabla 1 presentamos las imágenes organizadas según el tipo de silueta corporal o acción y composición final del corpus de análisis. En la Tabla 2 presentamos un ejemplar de cada categoría de tipo de silueta o acción. 
Tabla 1

Imágenes seleccionadas por tipos de siluetas

\begin{tabular}{lcc}
\hline Categoría & $\begin{array}{c}\text { Total de piezas recolectadas } \\
\text { en esta categoría }\end{array}$ & $\begin{array}{c}\text { Total de piezas selecciona- } \\
\text { das para el análisis, según } \\
\text { categoría }\end{array}$ \\
\hline Siluetas ideales & 286 & 5 \\
\hline Cuerpos problematizados & 7 & 1 \\
\hline Cuerpos reivindicados & 12 & 3 \\
\hline Acciones para cuerpos prob- & 9 & 2 \\
\hline lemáticos & 22 & 2 \\
\hline Acciones típicas cuerpos ideales & 336 & 13 \\
\hline Total & & \\
\hline Fuente: Elaboración propia. & &
\end{tabular}

Tabla 2

Ejemplares por cada criterio

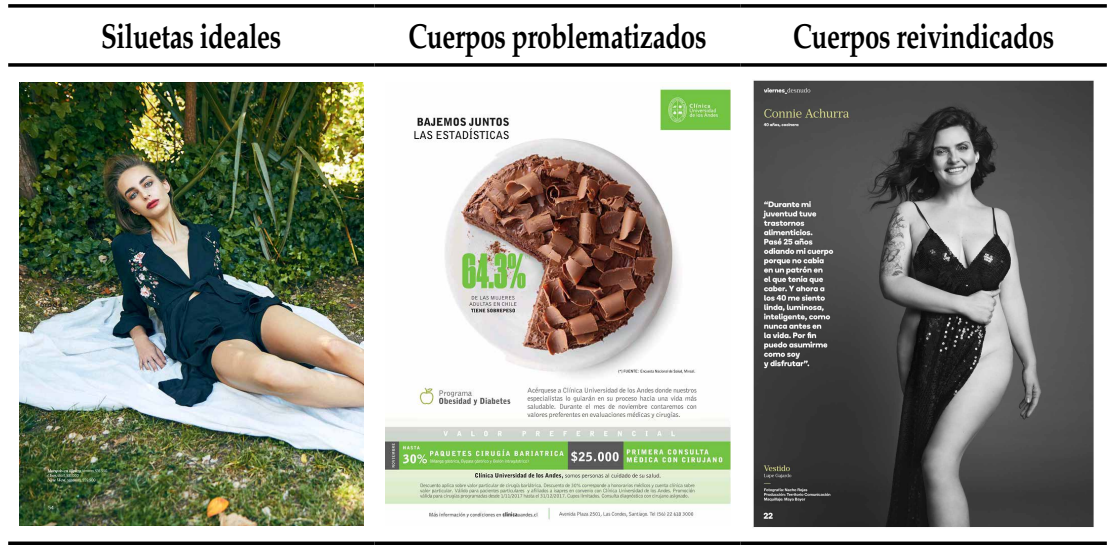

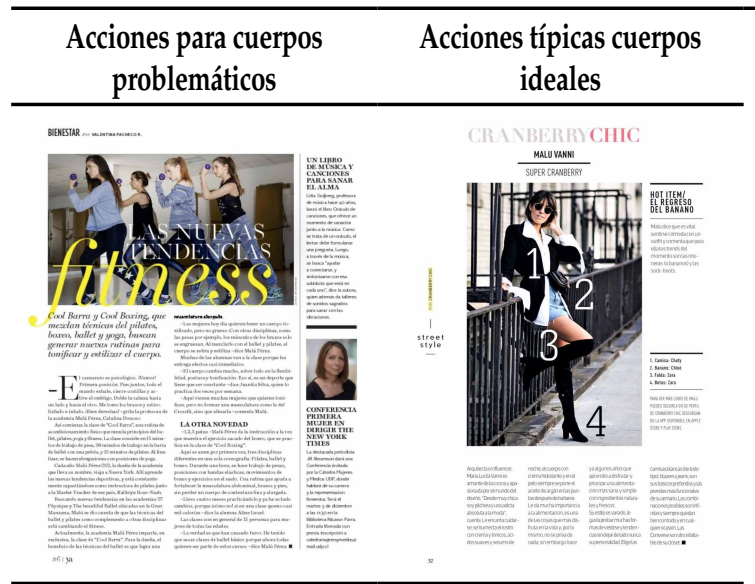

Fuente: Elaboración propia. 


\section{c) Estrategia de Análisis}

Considerando que en ciencias sociales se ha privilegiado el análisis de textos, co1ntamos con escasas herramientas teórico-metodológicas para trabajar con imágenes (Coleman, 2013). Inspirados importantemente por los nuevos materialismos y el giro afectivo, principalmente desde el trabajo de Rebecca Coleman (2013), desarrollamos un análisis que apuntara a describir la mayor cantidad de relaciones posibles desde cada imagen. A esto lo hemos llamado análisis difractaría de imágenes, inspirados en las propuesta "pensar con teoría" de Jackson y Mazzei (2018). Para esto trabajamos en dos fases, en primer lugar, para cada pieza preguntamos:

1. ¿Qué hace cada imagen? Considerando que las imágenes analizadas son de medios o publicidad, no son accidentales, por tanto, preguntamos por su acción;

2. Nombramos y describimos la acción en términos generales;

3. Justificamos la acción propuesta, esto es ¿por qué pensamos que la imagen hace eso y no otra cosa?

Luego, para cada imagen definimos un conjunto de relaciones dentro de las cuales estas se insertan. Esto implicó pensar más allá de las publicidades o artículos y para esto, en varios casos consultamos material adicional (por ejemplo, a los productores de las revistas). Los tipos de relaciones que consideramos con son los siguientes:

a. Participantes. Inspirados en la noción de actante (Latour, 2008) definimos un participante como algo o alguien con un rol en una estructura narrativa. Interesa qué o quienes participan, incluidos agentes no humanos como potenciales agentes. Así, para cada imagen preguntamos ¿Qué o quiénes son esenciales para las acciones que se realizan en las imágenes?

b. Temporalidades. Las temporalidades tradicionalmente han sido estudiadas desde una perspectiva lineal (pasado - presente - futuro). Desde los nuevos materialismos, la temporalidad se considera multidireccionalmente (Coleman, 2014), donde existen múltiples posibilidades: el pasado se trae al presente, el pasado 
es proyectado en el futuro o se mira al pasado desde el futuro, por mencionar algunas alternativas. Para analizar esta dimensión buscamos todas las referencias temporales en la imagen (día, momento, mes, año). Buscamos responder a las preguntas: ¿Qué temporalidades estructuran la acción y cómo las acciones estructuran las temporalidades?

c. Espacios. Consideramos los espacios del mismo modo que las temporalidades. Son, de algún modo, su anverso. Así, para cada imagen identificamos ¿Qué espacios estructuran la acción y cómo las acciones estructuran los espacios? Si bien estas dos categorías siempre aparecieron reflejándose entre ellas y se podrían haber unido, las mantuvimos separadas para favorecer descripciones más densas.

d. Estéticas y afectividades. Analizamos las estéticas inspirados en la noción de intertextualidad (Fairclough, 2003), esto es, la identificación de diversas estéticas nos permitiría vincular las imágenes con otras imágenes, cuerpos, textos, cosas y otros. Estudiamos las estéticas como opciones significativas para dar vida a una cosa o fenómeno (Tiainen, Kontturi y Hongisto, 2015). Para cada imagen preguntamos ¿Cuáles son las estéticas presentes en las imágenes y qué asociaciones se realizan a través de las estéticas?

Las primeras imágenes fueron realizadas en equipo, cuando la ruta de análisis estuvo acordada, cada miembro del equipo analizó una o varias imágenes, para luego consensuar grupalmente el análisis final. Además de un texto escrito, para cada imagen se construyó una red en el software Atlas.ti como la que se presenta en la Ilustración 1. 
Ilustración 1

Ejemplo de Red de Análisis

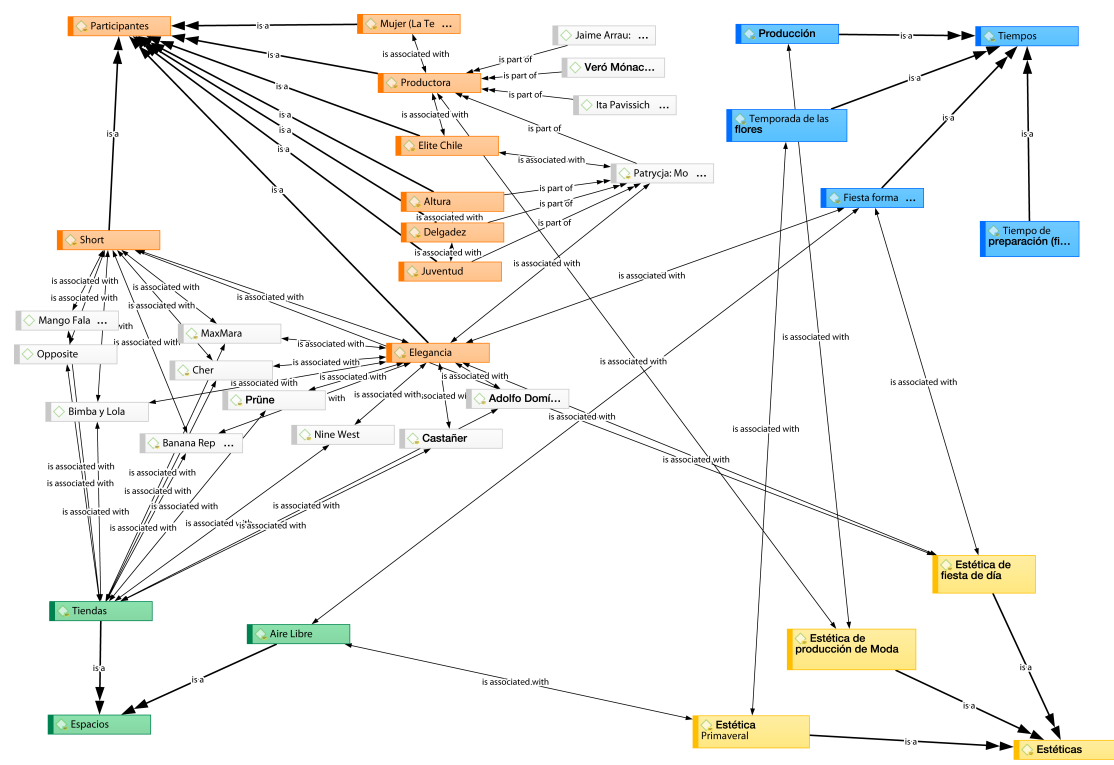

Fuente: Elaboración propia.

Finalmente, se realizó una síntesis de todos los análisis e, inspirados en el análisis temático (Braun y Clarke, 2006), describimos cuatro tipos de siluetas con sus respectivos significados, valoraciones y acciones típicas asociadas. Considerando que cada imagen contiene únicamente un tipo de cuerpo, cada una contribuyó a describir un tipo de silueta corporal y/o sus acciones.

\section{RESULTADOS}

Las siluetas descritas, junto con sus significados, valoraciones y prácticas, se articulan debido a distintos asuntos. Es decir, cada tipo de cuerpo se asocia a un grupo de cuestiones específicas. No funcionan necesariamente como un espectro que va desde una silueta ideal a una rechazada, sino como categorías que se relacionan unas con otras de distintas formas.

En los análisis describimos cuatro tipos de siluetas, las hemos nominado por el significado al que tienden a asociarse: elegancia, atractivo, felicidad y enfermedad. Si organizamos el corpus de imágenes según estas categorías, las imágenes se distribuyen del siguiente modo: 
Tabla 3

Imágenes organizadas según tipos de siluetas descritas

\begin{tabular}{lc}
\hline Tipos de siluetas descritas en el análisis. & $\begin{array}{c}\text { Cantidad de imágenes según tipo de } \\
\text { silueta identificada }\end{array}$ \\
\hline Silueta de la elegancia & 7 \\
\hline Silueta del atractivo & 1 \\
\hline Silueta de la felicidad & 3 \\
\hline Silueta de la enfermedad & 2 \\
\hline Total & 13 \\
\hline
\end{tabular}

Fuente: Elaboración propia.

Como se puede apreciar en la Tabla 3 la silueta del atractivo no cuenta con muchas imágenes, por tanto, no pudimos caracterizarla con el mismo nivel detalle que el resto de las corporalidades.

\section{SILUETA DE LA ELEGANCIA}

El primer tipo de silueta ideal es de extrema delgadez. Corresponde a un cuerpo femenino, donde se destaca en el rostro, cuello, extremidades y abdomen. La delgadez en todas estas siluetas va acompañada de la altura y la juventud. Esta es la silueta más común dentro de las imágenes analizadas.

Un ejemplar típico de este tipo de silueta se presenta en la imagen a continuación: la delgadez se destaca en un rostro enjuto de mejillas prominentes, en un cuello extremadamente delgado (se destaca el esternocleidomastoideo, músculo que en su inserción al esternón forma una " $\mathrm{v}$ " y que en personas muy delgadas es más prominente), las extremidades — sobre todo las piernas— son muy largas y delgadas.

Los ángulos de las fotografías se utilizan estratégicamente para destacar que las piernas de la modelo son muy largas (quien mide 1,79 metros de acuerdo con el catálogo de Elite Model). La altura sobresale sobre todo a través del ángulo de las fotografías. Y, por último, la juventud se juega en una serie de características, la primera es una ausencia total de flacidez, no hay manchas en la piel de ningún tipo, no hay ninguna arruga. El cabello es brillante, abundante y no tiene canas. Aporta al aspecto juvenil el uso de colores fuertes (generalmente 
se asocian los colores más opacos con la vejez). También da un aspecto juvenil el peinado más desordenado, como algo que fue arreglado rápidamente o se le dedicó escasa atención.

\section{Imagen 1}

Ejemplo Silueta Extremadamente Delgada

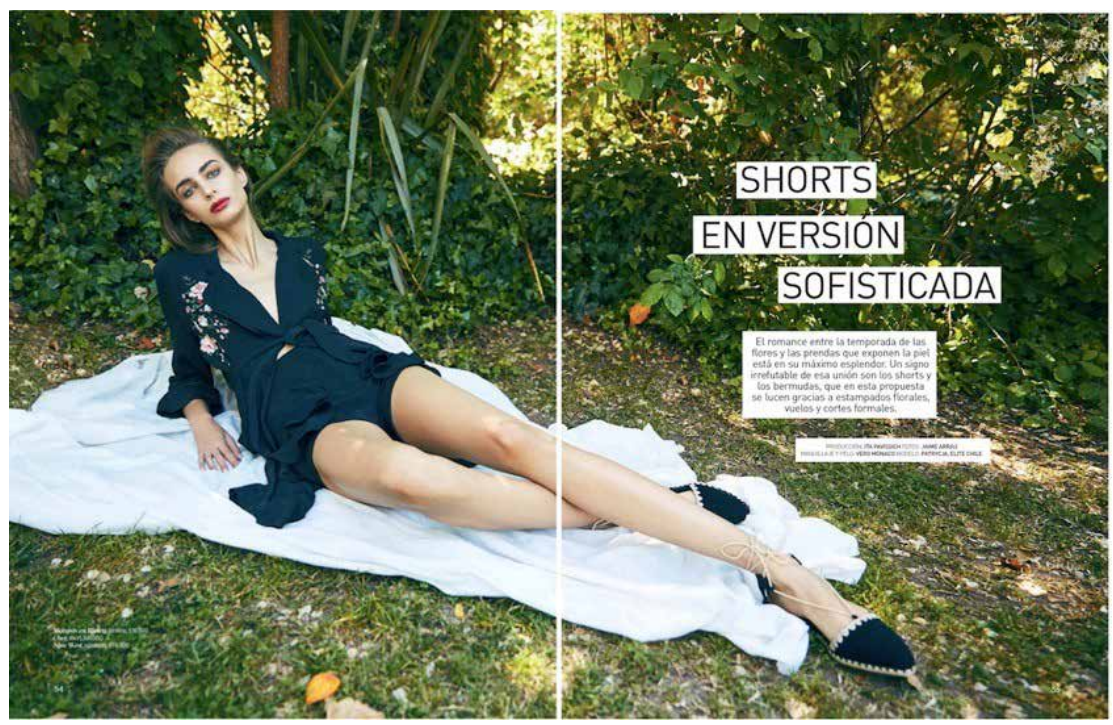

Fuente: Revista Mujer, La Tercera.

Las siluetas ideales generalmente son presentadas sin textos, es decir, la imagen no requiere de explicación. Por otra parte, para estas siluetas no se caracterizan en mayor detalle las acciones típicas para lograrlas o mantenerlas. Postulamos que, en este sentido, son lo normal o lo esperado. Se presentan como algo que es, con escasas o nulas referencias a las acciones para su constitución. En caso de presentarse estas acciones, el énfasis más que en la acción misma, está en la estética de la acción. Dicho de otro modo, se presentan las acciones estilizadas.

Por ejemplo, en un artículo breve sobre una influencer, esta está es descrita en los siguientes términos:

"Le encanta cuidarse, se humecta el rostro con crema y tónicos, ácidos suaves y serums de noche, el cuerpo con crema hidratante y en el pelo siempre se pone aceite de argán en las puntas después de bañarse. Le da mucha importancia a la alimentación, es una de las cosas que más disfruta en la 
vida y, por lo mismo, no se priva de nada, sin embargo hace ya algunos años que aprendió a disfrutar y priorizar una alimentación más sana y simple con ingredientes naturales y frescos". (Imagen R131).

El trabajo de belleza, de esta manera, no se vivencia como una obligación, sino que se estiliza como algo que se disfruta: a la influencer le gusta echarse cremas, tónicos y serums, disfruta de cuidar su nutrición y no es que vigile aquello que come, privándose constantemente, sino que aprendió a gozar con la alimentación saludable. Así, no es que únicamente se debe dar forma al cuerpo, sino que esto debe hacerse con cierta estética; como algo que no requiere mayor esfuerzo y que se disfruta.

Con el ejercicio ocurre algo similar, si tomamos el artículo "Las nuevas tendencias del fitness" (ver Imagen 2) la imagen con que se promociona el estudio de danza (diferenciado de forma explícita de un gimnasio en el texto), corresponde a mujeres con un atuendo que obedece a una estética conocida como urbana deportiva. Están peinadas, con una tenida combinada (en inglés, tienen un outfit). 


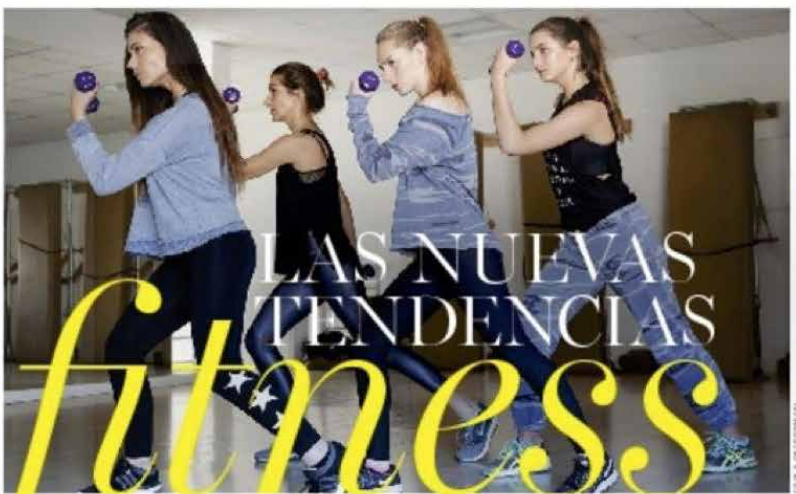

UN LIBRO

DE MUSICA Y CANCIONES PARA SANAK EL AL.MA

Iitta Goijerg, profesora id minica hoce 40 arios tanzó el litro Oraculo de cardiones que offrece ur marrento de sarnoción junto a la misica. Comb uno regetanta lurge a traves de la mivica. se busca "ayutar a conectives, y intenizare coness estis en cada urso", dice la sutora, quien adernik da talere de scridos sagrados

Cool Barra y Cool Boxing, que mesclan técnicas del pilates, boxeo, ballet y yoga, buscan generar nuevas rutinas para tonificar $y$ estilizar el cuerpo. I cansancio es psicológico. Namios!
Primera posición. Pies juntos, todo el
mundo exhale, cierre costillas y ac-
un live el oinhligo. Doble la cabeza hacia Exhalo e inhala. itien derectas! -grita la profesara de

Así eomienza la clase de "Cool Barra", una rutina de acondicianamiento fisico que ruexcla principios del batllet, pilates, yoga y fitness, La clase consiste en 15 minutos de trabajo de pesa, 30 mimitos de trabajo en la barra de ballet con una pelota, $\mathbf{y} 15$ minutas de pilates. $\mathrm{Al}$ finalizar, se hacen elongaciones con posiciones de yoga.

Cada año Malú Pérez C33\%, la duenia de la acsadernia que lleva su numbre, viaja a Nueva York. Alli aprende las nuevas tendencias deportivas, y estí constantemente capacitándose como instructara de pilates junt. a la Master Teacher de ese pair, Kathryn Rosa-Nash. Buscando ruevas tendencias en las acadernias 57 Physiquey The beautiful Bollet ubicadas en la Gran Manzana, Malú se dio cuenta de que las técnicas del ballet $y$ pilates como complemento a otras discip linas extà cambiando el fitness.

Actualmente, la scademia Malủ Pérez imparte, en exclusiva, la clase de "Cool Barra". Para la dueña, el beneficio de las técnicas del ballet es que logra una

\section{neruonisturesterende}

- Las mujeres hoy dia quieren tener un cuerpo tonificado, pero no frueso. Con otras disciplinas, eorno las pesas por ejemplo los músculas de los brazois wolo se engruesan. Al mexclarlo con el ballet $y$ pilates, el cuerpo se estina y estiliza -dice Malú Pérex. Muchas de las alumnas van a la clase porque len entregu electos casi inmediatos.

-El cuerpo cambia mucho, sobre todo en la flexibi. lidad, posturay tonificacicon. Hso si. es un deporte que tiene que ter constante -dice Juanita Silva, quien lo practica dos veces por semana.

-Aqui vienen muchas mujeres que quieren tonificar, pero no formar una musculatura como la del Crossfil, sino que afinarla-comenta Mals.

\section{LA OTRA NOVEDAD}

$-1,2,3$ patea - Malá Pérez da la instruoción a la vee que muestra el ejercicia sacado del boxeo, que se pra. tica en la clase de "Covl Boxing?.

Aqui se unen por primera vez, tres diseiplinas diferentesen una sola coreografia: Pilates, ballety hoxes. Duranle una hurn, se hace irahajo de presas, posicienes con bandas elásticas, mowimientos de boxes y ejercicios en el suela. Dna rutina que ayuda fortalecer la musculatura abdominal, brazas $y$ piex, sin perder un cuer po de contextura fina y alargada. - L.levo cuatro meses practicándolo y ya he notado cambios, porque iovimo no! si en ana clase querno cad mil calorias - dice la alumna Aline Lsrael.

Lasclases son en peneral de 15 personas para mujeres de todas las edades.

- L.u verdad es que han causada furos. He tenida que sacar clases de ballet básion parque ahora todas quieren ser par le de estos cursos -dice Malú Térez. ibraciones.

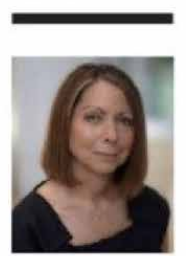

CONFERENCIA PRIMIERA MUJER EN DIRIGIR THE NEW YORK TIMES

La destrada periodsta ill Abrarmon dara una Conferencia invitads por la Catedra Mujeres y Medos UDP, donde hablara de su carrera yla representasion fernerina Serad rartes 5 de dideribre a las 1130 enla Bitliotera Nicanor Parra Entrada liberada con presia inscripciona catedramujeresymedios mail.udpel

361 ya

Fuente: Revista Ya, El Mercurio.

El estudio de danza se encuentra en un centro comercial abierto, y como se puede apreciar en la Imagen 3, cuenta con grandes ventanales que permiten mirar hacia el interior. Entonces, el recinto no es únicamente un lugar para estilizar el cuerpo, como afirma su dueña, Malú Pérez en el artículo ("Las mujeres hoy día quieren tener un cuerpo tonificado, pero no 
grueso"), sino que también esta misma acción se realiza de acuerdo con una estética escénica como podría ser análogamente el ballet o la danza contemporánea. La evitación de un cuerpo grueso o musculoso es consistente con que, incluso, aquellas siluetas que aparecen haciendo ejercicio son extremadamente delgadas y de estructura ósea prominente. No tenemos en la muestra imágenes de siluetas con musculatura marcada.

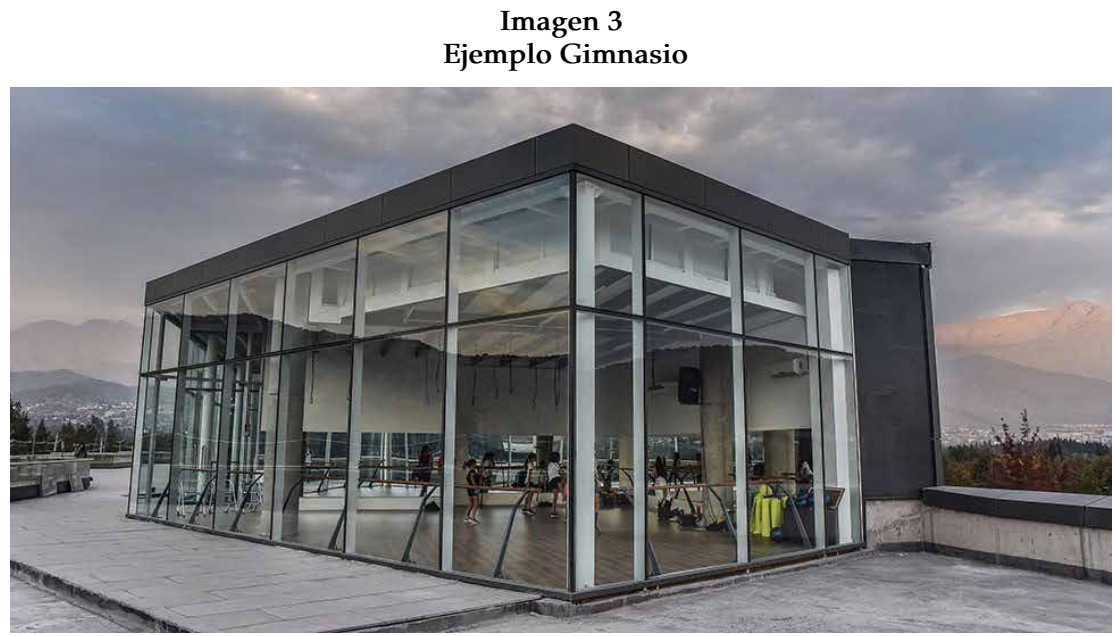

Fuente: sitio web Estudio Malú Pérez (https://www.maluperezonline.cl/).

En definitiva, este tipo de silueta se presenta como ausente de trabajo, o más bien, las acciones para constituir esta silueta se adjetivan como bellas y placenteras para quien la realiza.

Esta silueta la hemos asociado al significado de la elegancia. Lo común en todas las siluetas extremadamente delgadas que encontramos, es que son sumamente elegantes. Por ejemplo, en el análisis de la chocolatería La Fête (ver Imagen 4), el uso de una figura femenina extremadamente delgada es parte de los recursos para adjetivar la marca como elegante. La extrema delgadez no es, ciertamente, el único recurso que se utiliza para esto (la mujer es blanca, se hace referencia a una estética francesa, el emplazamiento de la tienda mezcla elementos estéticos de un museo y una joyería), pero la delgadez es esencial. La imagen no funcionaría con una mujer más gruesa?

En general esta imagen no se presenta como erótica en sí misma, en tanto que debe ser erotizada. Es lo que hemos llamado una ortopedia de la erotización. Por ejemplo, en este caso, la modelo juega con la noción 
de desnudo cubriendo su brazo con algo que parece ser un tatuaje y/o una prenda de encaje. En general las siluetas delgadas cuentan con estos recursos o 'utilerías' para ser erotizadas, lo que hace suponer que no son eróticas en sí mismas (de hecho, no todas las siluetas extremadamente delgadas que analizamos se presentan erotizadas).

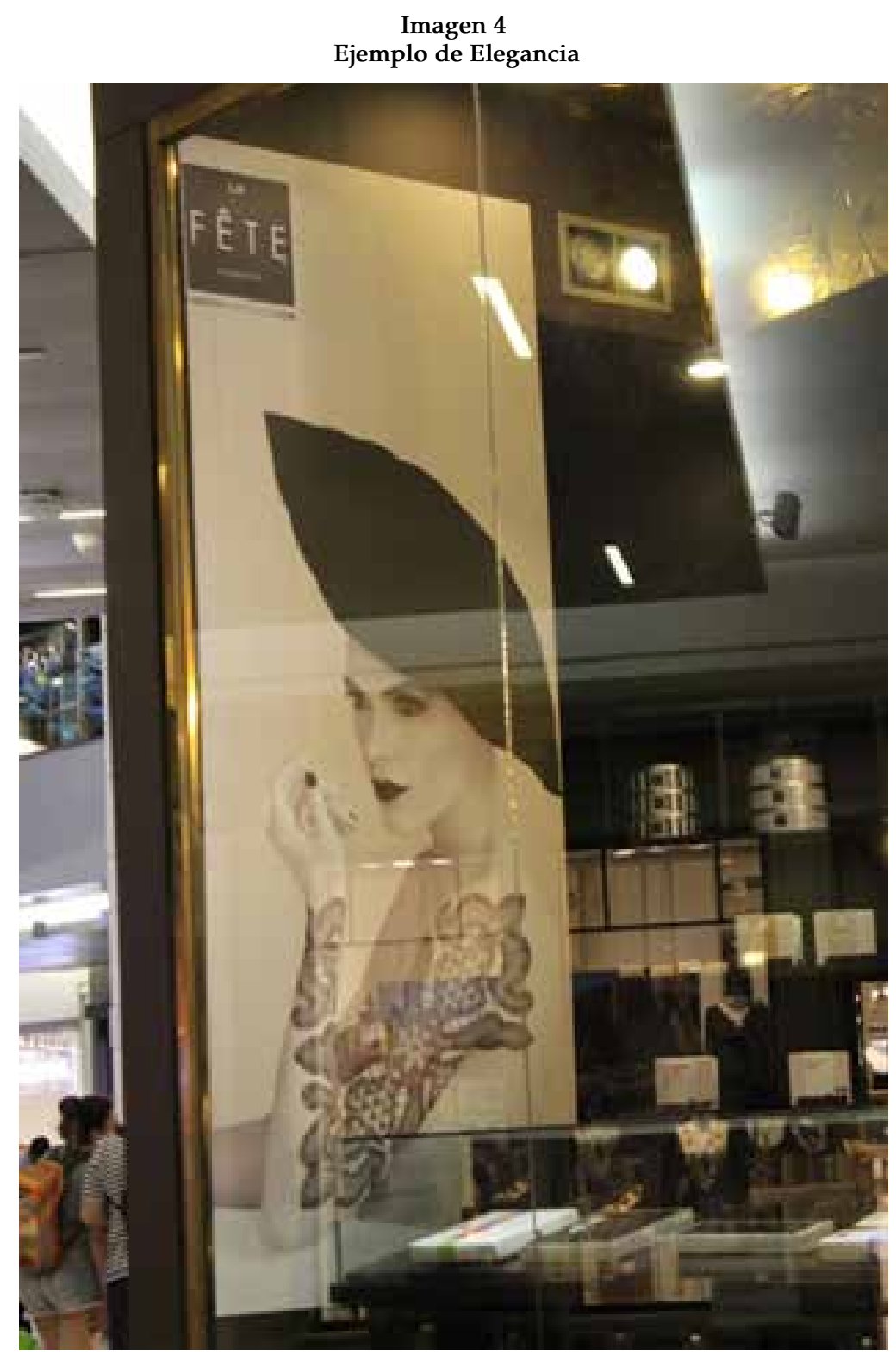

Fuente: Fotografía Mall Costanera Center. 
Por último, en cuanto a la valoración, como se puede apreciar en la estilización de la acción, se valora positivamente o al menos no se presenta como problemática para quien la posee. No obstante, como mostraré más adelante, sí se considera problemática o se valora negativamente. Es decir, si bien se valora positivamente, no es por ello a-problemática.

\section{Silueta del Atractivo}

La diferencia fundamental con la silueta anterior es que la delgadez no es tan extrema. Por ejemplo, corresponde a una silueta con un busto grande, una cintura que no es tan pequeña como la de otras imágenes y no destacan los huesos de la modelo. No es una delgadez extrema al punto que se atenúan o pierden caracteres sexuales secundarios tales como:

- Senos desarrollados;

- Mayor nivel de grasa subcutánea, especialmente en el rostro, glúteos y muslos;

- Caderas más anchas;

Esta es una diferencia con otras modelos de delgadez más extrema, donde dichos rasgos tienden a desaparecer. A diferencia de la silueta anterior, esta silueta se presenta como atractiva o erotizada en sí misma. No requiere de ortopedia para erotizarse, pues, por ejemplo, en la Imagen 5 , podemos observar que, si bien se promueve ropa de verano, la modelo se encuentra con una proporción importante del cuerpo tapada. Si la primera silueta se asocia con elegancia, esta se asocia con la atracción ${ }^{10}$. 


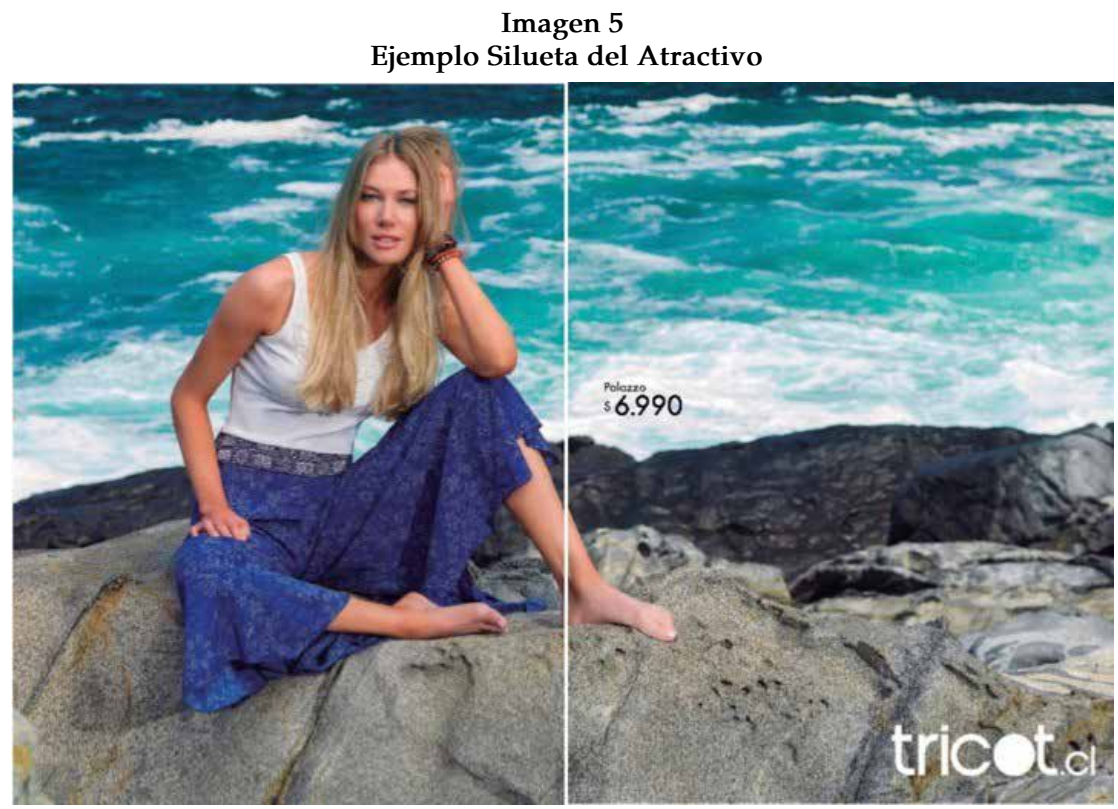

Fuente: Revista Mujer, La Tercera.

Esta silueta fue atípica en la muestra, por tanto, no encontramos imágenes que nos indicaran sus acciones típicas o su valoración. Por último, del mismo modo que la primera silueta, esta se caracteriza únicamente con imágenes (sin textos).

\section{Silueta de la Felicidad}

Los análisis nos permiten identificar una gordura socialmente aceptable que he nominado como silueta de la felicidad. La he descrito como gordura, y no obesidad, porque su carácter médico es irrelevante, por lo que lo importante es que quienes poseen esta silueta se describen a sí mismas como gordas en algún sentido.

Ejemplar de esta forma de siluetas es la imagen de la cocinera Connie Achurra en la sección Viernes Desnudo en el diario La Segunda (ver Imagen 6). Su tamaño probablemente no representa un problema salud, por tanto, su gordura es más un asunto social que médico. Connie Achurra es una cocinera de comida saludable, por tanto, su cuerpo encarna justamente esta idea: que se puede ser sano sin ser delgado. 
Imagen 6

Ejemplo Silueta de la Felicidad

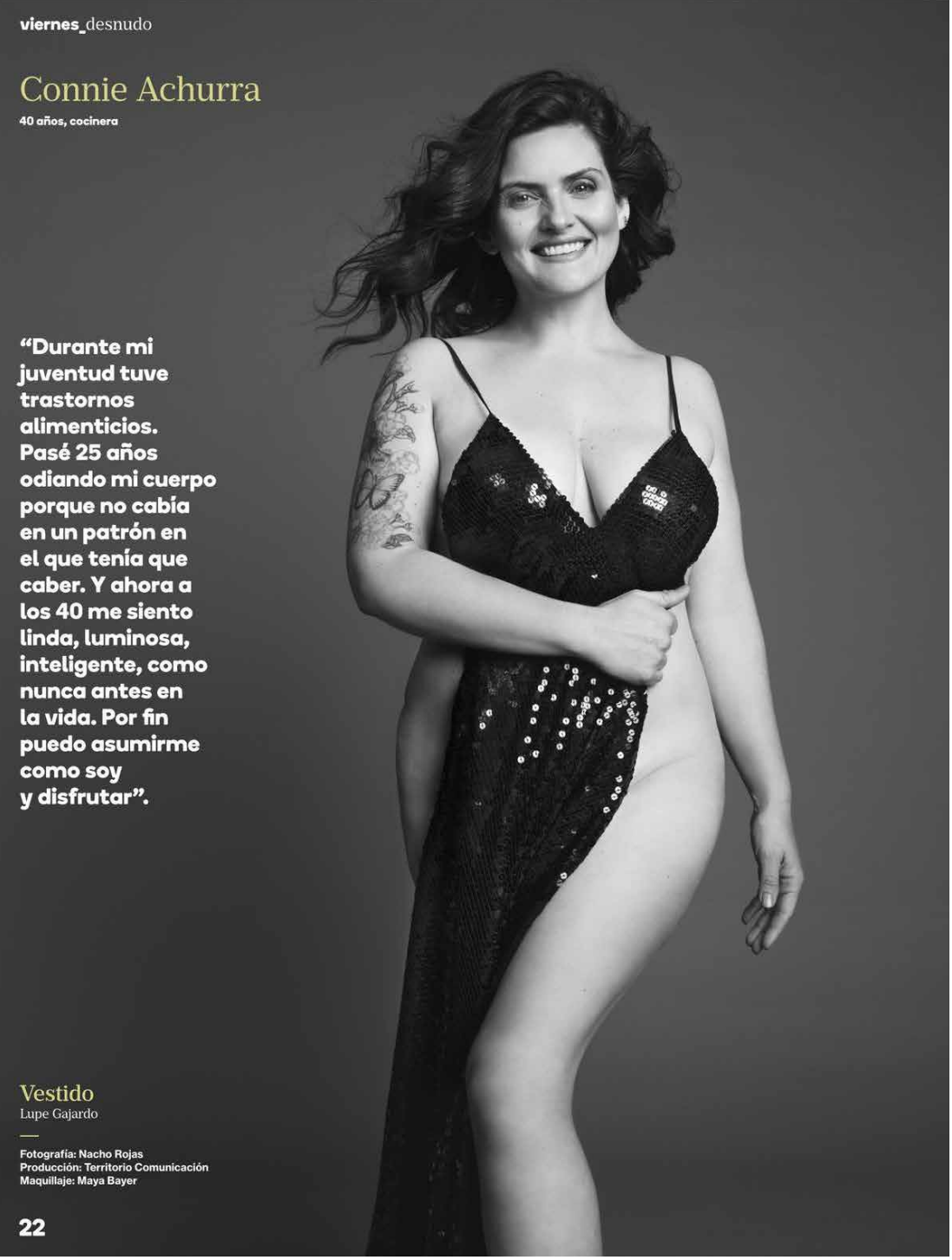

Fuente: Revista Viernes, La Segunda

Sobre esta silueta, cabe destacar que posee algunos atributos bien específicos: se encarna en un cuerpo de una raza específica (piel clara), donde todo se encuentra bien cuidado (cabello, piel). Por otra parte, no se trata de cualquier gordura; posee dos características particulares. En primer término, el rostro es delgado, sobre todo la línea de la 
mandíbula. Además, conserva una curvatura femenina, sin perder las proporciones de caderas y cintura. Es una silueta tradicionalmente femenina pero engrosada. No es una gordura desbordada, la gordura del rollo que rebasa el cuerpo, donde los brazos son gruesos y la grasa se acumulada en la espalda y abdomen, haciendo que pierda la silueta considerada típicamente como femenina. En segundo lugar, son cuerpos con una narrativa, es decir, son cuerpos con una explicación. Socialmente, sabemos que aquello que requiere de una explicación es porque de algún modo escapa a la norma social. El texto puede no ser largo, pero nos remite a una narrativa sobre el cuerpo presente en varias imágenes y también en otros contextos.

La idea de cuerpos que vienen acompañados con narrativa es particular. En investigación cualitativa se tienden a privilegiar lo textual o, en caso de considerarse lo corporal o la imagen, se realiza omitiendo el texto. Sin embargo, en el tipo de indagación que realizamos, las consideramos como asuntos embrollados, donde algunos cuerpos están rodeados por textos, inmiscuidos en palabras o, dicho de otro modo, son corporalizaciones de relatos. De esta forma, lo que presento a continuación corresponde justamente al tipo de narrativa que tienden a adherirse a estas siluetas.

La estructura narrativa se articula en dos momentos, el primero es de "exigencia por adelgazar" con conductas extremas como vómitos auto provocados, laxantes, pastillas para adelgazar o dietas estrictas. El ideal de la extrema delgadez juega un rol central en este punto de la narración. Luego viene un quiebre, puede ser con un motivo específico o desconocido. Este lo llamaremos como "la reconciliación con el cuerpo". Es trabajoso, puede involucrar terapia, y es largo; toma años. El segundo momento es de "aceptación del cuerpo". No se pelea con el cuerpo, sino que se acepta (de ahí que tiene sentido la idea de reconciliación).

Si el primer momento está comandado por el ideal de la delgadez, este último se mueve por el amor a sí misma y ser feliz. Las conductas respecto del cuerpo no parecen variar mayormente, es decir, no es que se deje de vigilar la alimentación y el ejercicio, más bien se hace con una lógica distinta. Este cambio de lógica implica un cambio de intensidad: no es no comer, es comer saludable. No es hacer ejercicios hasta quedar exhausta, es mantener un equilibrio. 
En este sentido, proponemos que las acciones típicas del mismo modo que para la silueta elegante, más que un foco en la acción es en la lógica o estética de la acción, en este caso, es una práctica que no debe ser extrema y cuyo objetivo es ser feliz y saludable.

Para el análisis de la narrativa recurrimos a material (textual) que está supuesto en la imagen. Para el ejemplo de Connie Achurra recurrimos al prólogo de su libro de cocina: Cocina Sana y Feliz. En el texto de la publicidad, esta se presenta como una cocinera que "se asume como es y disfruta". Se destaca que tiene 40 años. La edad es relevante, pues indica el momento del ciclo vital en que logra aceptar su cuerpo y quererse tal cual es. De esta manera, aceptarse con un cuerpo que no es el ideal involucra mucho tiempo en la vida de una persona: en ese caso, la cocinera pasó 25 años odiando su cuerpo hasta que lo logra aceptar a los 40. El detalle de esta historia está en el prólogo de su libro:

"Antes de compartir mis recetas, quisiera contarle un poco de mi historia para entender por qué quise hacer este libro. [...]

Durante mi adolescencia, y hasta aproximadamente los veinticinco años, tuve trastornos alimenticios severos. Entre ellos, algunos episodios de bulimia. En esta época me alimenté de productos light, procesados, comidas con calorías vacías, bebidas gaseosas. Y si de algo me preocupaba, era de revisar siempre la cantidad de calorías. No me importaba si eran tóxicas para mi organismo, o si me estaba haciendo daño; lo único que quería era estar flaca y, para eso, debía comer la menor cantidad posible. Esta baja de ingesta, por supuesto, se combinaba con períodos de ayuno y muchísimos atracones, que terminaba purgando de cualquier manera: vómitos autoprovocados, laxantes, etcéteras ${ }^{\prime 11}$.

La comida saludable es una respuesta a otra forma de alimentación, basada únicamente en la restricción de las calorías. Esta manera de comer es efecto de una relación con el cuerpo: "lo único que quería era estar flaca". Es una práctica basada en números: la cantidad de calorías ingeridas. El quiebre de esta relación con el cuerpo se da al tener hijas:

“Me sané y me volví a enfermar muchas veces. Vivía en un equilibrio precario y angustiante pero todo se acabó cuando nació mi primera hija Julieta y, al año siguiente, mi hija Luciana; convertirme en mamá me dio la claridad para entender que tenía que salir de la bulimia, que quería estar sana y feliz para ellas y que no quería, por ningún motivo, heredarles $\mathrm{mi}$ 
relación tormentosa con la comida. Fue en ese momento que decidí hacer un cambio profundo"12.

El primer cambio que menciona Connie es "Me hice amiga de la comida". Sin embargo, esto no implica la ausencia del control y vigilancia de la alimentación. La primera parte del párrafo es similar a la descripción de una dieta:

“El primero y más importante paso fue eliminar de mi vida el azúcar blanca, en todas sus formas. Del mismo modo, erradiqué los refinados y las bebidas gaseosas (no se imaginan lo que me costó; mi nivel de adicción era tremendo y recaí muchas veces), y así volví a reencontrarme con las frutas, verduras, legumbres y frutos secos, incluso con las paltas, nueces, uvas y plátanos que siempre me había prohibido por ser 'muy calóricas'”13.

Así, en la primera parte del párrafo se describe aquello que se debe eliminar: el azúcar blanco, los alimentos refinados y las bebidas gaseosas. Se explica también por cuales se debe reemplazar: frutas, verduras, legumbres y frutos secos. Lo novedoso es que se incluyen alimentos altos en calorías: paltas, nueces, uvas y plátanos. El criterio es que son saludables (en vez de calóricos). Pero la principal diferencia no está en los alimentos prohibidos y permitidos, sino en el foco:

“Así, empecé a alimentarme con otros ingredientes, pero no ya desde el miedo, sino desde el amor. Cambié el foco de las calorías por el de los nutrientes y empecé realmente a 'alimentarme'. Ese fue el cambio de switch definitivo" ${ }^{14}$.

Las transformaciones que se relatan en el texto son dos. La primera es que ya no se come con miedo sino con amor. Es decir, no se teme a los alimentos o a sí misma. Se puede interpretar que, en esta modalidad restrictiva, el miedo es a pasarse de la cantidad de calorías permitidas. Nutrirse desde el amor, en cambio, se relaciona con la idea de cuidar el cuerpo a través de lo que se ingiere, se utiliza alimentación en su doble acepción, como mantener un ser vivo, pero también como fomentar el desarrollo de hábitos, sentimientos o estados de ánimo. Esto se relaciona con la idea de nutrir el cuerpo y el alma. De hecho, el título a continuación del libro (Cocina Sana y Feliz) es: Comida y nutrientes para el alma. 
La segunda transformación se refiere al foco de las calorías por los nutrientes; así, lo que interesa no es la restricción de calorías sino equilibrar todos los nutrientes. Como efecto, el cambio en la conducta no es la ausencia de restricciones o de vigilancia de la ingesta, pues se prohíben y remplazan algunos alimentos. En este sentido difiere poco de lo que se ha definido tradicionalmente como una dieta. La diferencia más radical está en el modo de comprender la alimentación, pues esta deja de entenderse como un comportamiento calórico, y más bien se asume como el cuidado del cuerpo y el alma. Esto se aprecia en uno de los párrafos de cierre:

\footnotetext{
"Mi propuesta no tiene que ver con dietas extremas, con alimentarse con un solo grupo de alimentos, ni con volvernos locos comprando productos importados y rebuscados. Nada de eso. Mi invitación es a alimentarse con comida de verdad, a fijar el foco en los nutrientes, en la calidad del combustible que usamos"15.
}

En este sentido, el cambio de foco es comer alimento verdadero.

En resumen, se establecen dos momentos, donde el tránsito del primero al segundo se describe como trabajoso y difícil; de hecho, se describe utilizando la metáfora de la rehabilitación (habla de 'adicción' y 'recaídas'). Una síntesis de estos dos momentos puede apreciarse en la Tabla 4.

Tabla 4

Comparación de momentos en narrativa de la felicidad

\begin{tabular}{ll}
\hline Primer Momento & Segundo Momento \\
\hline Se privilegian las calorías & Se privilegian los nutrientes \\
\hline Se busca ser flaca & Se busca ser sana y feliz \\
\hline Se alimenta con miedo & Se alimenta con amor \\
\hline Alimentación falsa (light, procesados, & $\begin{array}{l}\text { Alimentación de comida verdadera para el } \\
\text { cuerpo y el alma. }\end{array}$ \\
\hline 'calorías vacías') & Amiga de la comida \\
\hline Relación tormentosa con la comida & Se reconcilia con su cuerpo \\
\hline Se busca modificar el cuerpo &
\end{tabular}

Por último, si bien esta silueta presenta una valoración positiva, en términos generales, si consideramos que requiere de una explicación o que debe ir acompañada de un texto, podemos proponer que, al igual que en la silueta de la elegancia, dicha valoración no es absoluta. 


\section{Silueta de la Enfermedad}

Finalmente, tenemos la silueta de la enfermedad, la cual corresponde a la gordura médica, o sea, la obesidad. Este tipo de cuerpo no se muestra en las revistas, se problematiza o se refiere a través de un objeto, por ejemplo, en este caso, una torta de chocolate (ver Imagen 7).

\section{Imagen 7}

Ejemplo Silueta de la Obesidad

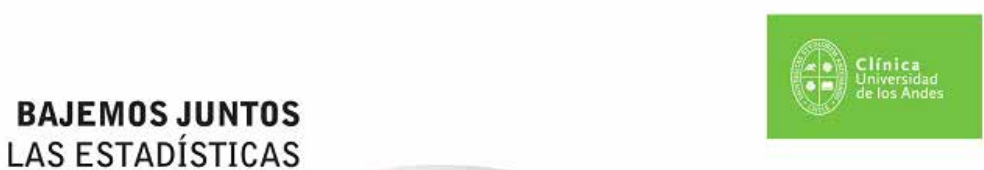
LAS ESTADÍSTICAS

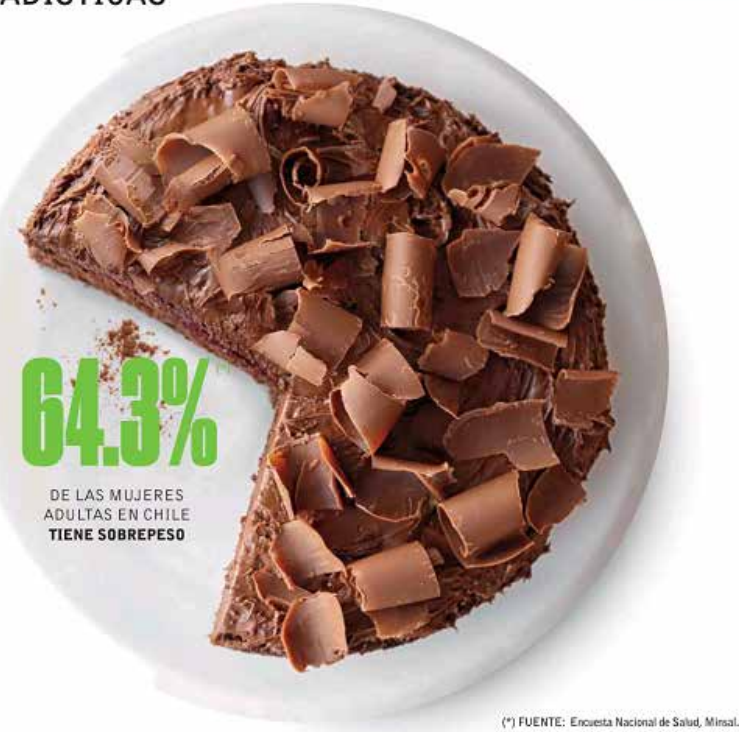

Acérquese a Clínica Universidad de los Andes donde nuestros especialistas lo guiarán en su proceso hacia una vida más saludable. Durante el mes de noviembre contaremos con valores preferentes en evaluaciones médicas y cirugias.

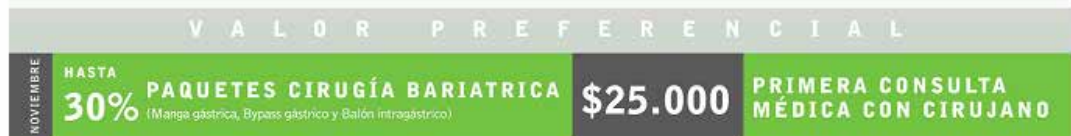

Clínica Universidad de los Andes, somos personas al cuidado de su salud.

Descuento aplica sobre valor particular de cirugia bariátrica. Descuento de $30 \%$ corresponde a honorarios médicos y cuenta clínica sobre valor particular. Valido para pacientes particulares y afiliados a isapres en convenio con Cinica Universidad de los Andes. Promoci

Más información y condiciones en clinicauandes.cl

Fuente: Revista Mujer, La Tercera. 
De manera similar a la silueta anterior, para este cuerpo se propone una narrativa con un quiebre.En esta imagen el sobrepeso se articula en tres registros:

1. El primero, y evidente, es el registro biomédico. El sobrepeso es un asunto que mide el Ministerio de Salud y se trata en un hospital, por especialistas médicos a través de evaluaciones y cirugías. El registro clínico parece estar más en la solución que en la problematización, es decir, es un problema que se resuelve médicamente, pero no se articula en estos términos;

2. El segundo registro es el estético. Este se constituye principalmente a través de los espacios;

el aviso es parte de un número especial que promueve Feria Mujer (una feria en que promueven $u$ ofertan distintos servicios para mujeres). Esta está dedicada prioritariamente a artículos de moda. En este contexto, se promociona el programa de cirugía bariátrica. También se construye temporalmente: es una oferta "ahora que viene el verano". Este registro de lo estético también se interpreta en que no se muestra un cuerpo con sobrepeso, sino que se remplaza por un objeto;

3. Por último, el sobrepeso se articula con un registro de lo moral. Este es efecto de la gula, de un apetito descontrolado y desmedido de quien ingiere individualmente una torta de chocolate. Es, además, una moralización femenina. Dicho de otro modo, el problema que se articula en la imagen es el sobrepeso femenino. Este dato es particularmente interesante porque de acuerdo a la Encuesta Nacional de Salud, el sobrepeso en mujeres tiene una prevalencia del 33,6\%, considerablemente más bajo que el 45,3\% en los hombres. En obesidad esta tendencia se revierte, pues hay más mujeres obesas $(30,7 \%)$ que hombres $(19,2 \%)$. En la publicidad se presentan los datos de obesidad y sobrepeso agregados, los cuales son casi idénticos para hombres $(64,5 \%)$ y mujeres $(64,4 \%)$. Entonces, no radica en la distribución de la obesidad y el sobrepeso la focalización en mujeres. Esta se entiende como efecto de que, por una parte, es una imagen publicitaria en la Revista Mujer, en el contexto de la Feria Mujer y, por la otra, como producto de la feminización de la gordura. En este sentido, si la obesidad y 
el sobrepeso son un problema que afecta tanto a hombres como mujeres, en su acepción más estética y moral es un trastorno predominantemente de mujeres.

De esta manera, a un problema de causa moral (un apetito desmedido), corresponde una solución clínica: la cirugía bariátrica, esta se presenta como un primer paso hacia una vida más saludable. En este sentido, se puede postular cierto solapamiento con la silueta anterior, donde la cirugía opera como una acción de corrección para luego instalarse en la silueta de la felicidad.

La Tabla 5 presenta una síntesis de los principales resultados.

Tabla 5

Síntesis de Resultados

\begin{tabular}{lllll}
\hline Silueta & Significado & Valoración & Acción tipo & $\begin{array}{l}\text { Forma en que se } \\
\text { representa }\end{array}$ \\
\hline $\begin{array}{l}\text { Silueta } \\
\text { extremadamente } \\
\text { delgada }\end{array}$ & Elegancia & $\begin{array}{l}\text { Positiva y } \\
\text { criticada }\end{array}$ & $\begin{array}{l}\text { Estilizada: sin } \\
\text { esfuerzo }\end{array}$ & $\begin{array}{l}\text { Imágenes de } \\
\text { cuerpos }\end{array}$ \\
\hline Silueta delgada & Atractivo & - & - & $\begin{array}{l}\text { Imágenes de } \\
\text { cuerpos }\end{array}$ \\
\hline Gordura & Felicidad & $\begin{array}{l}\text { Positiva }(\mathrm{y} \\
\text { negativa) }\end{array}$ & $\begin{array}{l}\text { Estilizadas: } \\
\text { Equilibrio y amor }\end{array}$ & $\begin{array}{l}\text { Imágenes de } \\
\text { cuerpos y texto }\end{array}$ \\
\hline Obesidad & Desmesura & Negativa & Cirugía & $\begin{array}{l}\text { Imágenes de } \\
\text { objetos y texto. }\end{array}$ \\
\hline
\end{tabular}

Fuente: Elaboración propia.

Como planteaba inicialmente, las distintas siluetas parecen asociarse con diversos asuntos, organizándose más como una constelación que como un espectro. La silueta deseada depende, en cierta medida, de otros objetivos; por ejemplo, ser elegante, feliz o atractiva.

En segundo término, si bien las siluetas tienen una dimensión prescriptiva, es relevante destacar que no es únicamente la forma de cuerpo y acciones para lograr aquello que se indica, sino también se prescribe que estas deben desarrollarse de acuerdo con una estética particular. De hecho, de la silueta de la elegancia a la silueta de la felicidad, las diferencias en las acciones indicadas no presentaban una gran variación: se recomienda hacer ejercicios y una vigilancia de la alimentación. 
La mayor diferencia está en la forma de llevar a cabo la acción o en lo que hemos llamado su estética. En la silueta elegante, mantener un cuerpo así, se indica como algo que no debe tomar esfuerzo, debe ocurrir espontáneamente. De hecho, el esfuerzo por mantener esta silueta es adjetivado y criticado como una conducta extrema. Por tanto, no es la silueta en sí misma la que es objeto de rechazo, sino las acciones desmedidas para sostenerla. La silueta de la felicidad, en cambio, tiene otra estética, su objetivo es el cuidado del cuerpo y el alma, nutrirse con alimento verdadero. Se ejercita y vigila la alimentación, pero no con el objetivo de ser delgada, sino saludable y feliz. La acción es similar, vigilar el movimiento y lo que se ingiere, pero se adjetiva y estiliza de manera diferente.

Por último, desde la silueta de la felicidad se critica la delgadez extrema, propia de la silueta de la elegancia. Como efecto, no existe una silueta ideal en términos absolutos. La silueta de la elegancia, aquella que se ha identificado en la literatura académica como deseable socialmente, no se encuentra exenta de críticas. Opera como referente, en tanto, que la silueta de la felicidad se sitúa como una alternativa a ella, pero no necesariamente como un ideal incuestionado.

\section{CONCLUSIONES}

Los resultados presentados, si bien son consistentes con la evidencia que muestra que la gordura es una condición altamente discriminada, muestran como las siluetas ideales se constituyen como un campo en disputa, en el cual se valoran diversos asuntos con relación a los cuerpos y el sí mismo. Si bien los análisis nos permiten postular que existen siluetas corporales femeninas más valoradas que otras, ninguna se encuentra exenta de críticas en tanto que la silueta de la felicidad, condensa una crítica hacia la silueta de la elegancia.

Irmgard Tischner (2013) plantea que, para el cuerpo femenino, se realiza una metonimia entre corporalidad y subjetividad. Es decir, las mujeres son construidas como determinadas por su cuerpo, donde su valía como sujeto se define por su corporalidad. En otras palabras, hay una metonimia entre sujeto y cuerpo para el caso de las mujeres, donde la calidad del self está dada por el tipo de cuerpo que se posee. Haciendo eco de esta propuesta, podemos plantear que los resultados presentados muestran que, en la relación con el cuerpo, las mujeres articulan una diversidad de asuntos, sin limitarse exclusivamente al control y 
la disciplina del hambre y el movimiento en la gestión corporal. En el cuerpo se juegan asuntos morales, como la felicidad, y estéticos, como la elegancia. La escasa presencia y variedad de imágenes corporales de varones, sumado a que en el pensamiento occidental lo masculino se asocia a la mente (Frost, 2011; Grosz, 1994) hacen que el cuerpo/sujeto femenino se constituye con las particularidades antes planteadas.

La especificidad para lograr una silueta ideal, esto es, no solamente mantener un cuerpo extremadamente delgado, sino realizarlo de manera espontánea, divertida y sin esfuerzo, constituyen una complejidad particular. Si seguimos la propuesta de Tischner (2013) que el valor del sujeto femenino está dado por su cuerpo, y consideramos que el cuerpo ideal no debe ser comprendido ni tratado como un trabajo arduo, complejo e ingrato, ello agrega una mayor dificultad a las prácticas que las mujeres deben realizar sobre su cuerpo o sobre sí mismas (pues en este caso son equivalentes): no es únicamente que deben ocuparse de sus cuerpos, sino que deben hacerlo ateniéndose a una estética, o si se prefiere, con una afectividad particular asociada ${ }^{16}$. Como una acción espontánea, que se disfruta y entretiene.

Si comparamos esto con el ideal de sujeto foucaultiano, que asumiremos como un sujeto masculino, para este se prescriben ideales (morales), pero también ciertas acciones para alcanzarlo (Foucault, 2002). El caso femenino constituye un lugar paradójico en este sentido, pues se prescribe un ideal, pero se niega el trabajo que debe realizarse sobre el cuerpo/sí mismo como un trabajo como tal.

La identificación de estas estéticas o afectividades asociadas a la vigilancia de la alimentación y el ejercicio que hemos identificado en los resultados, permiten comprender por qué las prácticas de cuidado y control del cuerpo femenino han sido tan difíciles de identificar y casi omitidas en el campo académico. Sandra Lee Bartky (1998) por ejemplo, identifica tres tipos de vigilancia y control corporal que son específicas al cuerpo femenino: las primeras se refieren justamente a las prácticas de disciplinamiento del tamaño del cuerpo, en segundo lugar, está la esfuerzo sobre lo gestos y movimientos para que sean suaves y delicados, y por último, propone las prácticas de "trabajo de belleza" que toman el cuerpo como una superficie de ornamento. En una línea similar, Samantha Kwan y Mary Nell Trautner (2009) hablan del "trabajo de belleza" que realizan las mujeres. Las autoras se concentran en "el trabajo de belleza y exploran las prácticas de belleza que los 
individuos realizan sobre sí mismo para obtener ciertos beneficios en una jerarquía social específica" (2009:50). La adjetivación de las prácticas de belleza como trabajo destaca, además de las gratificaciones, que es una actividad que requiere de destrezas, conocimientos, disciplina, recursos y tiempo.

En ambas propuestas, las autoras se concentran en la disciplina y el control sobre el cuerpo. Sin embargo, si agregamos a los análisis las estéticas o afectividades con las que se debe realizar dicha labor, tenemos como efecto (i) que es una empresa tremendamente compleja, pues se debe trabajar sobre el cuerpo, pero de forma tal que no aparezca como laborioso y (ii) es un mecanismo de control difícil de identificar, en tanto que se prescribe con una afectividad de disfrute y, en consecuencia, no se vivencia para quien lo realiza como laborioso o arduo.

Se requiere de futuras investigaciones para indagar en el modo en que las mujeres se apropian y lidian con estas normas culturales en su cotidianidad. Por último, respecto a las limitaciones del estudio, la noción de silueta fue un constructo complejo metodológicamente. Esto porque no existen cuerpos únicamente con siluetas, los cuerpos tienen siluetas, sexo, colores, tipos de cabello, etcétera. Por lo tanto, nociones más generales como cuerpo podrían ser más útiles para aprehender la complejidad que se articula en las figuras ideales y rechazadas para el cuerpo femenino.

En segundo lugar, futuras indagaciones deben considerar elementos raciales en los análisis. La mayoría de los cuerpos estudiados son de rasgos caucásicos, por lo que es probable que el tipo de racismo presente en Chile evite la aparición de cuerpos más curvilíneos al estilo Beyoncé.

(Recibido el 27 de marzo de 2019)

(Reenviado el 27 de decembro de 2019)

(Reenviado el 19 de enero de 2020) (Aprobado para su publicación el 21 de octubre de 2020) 


\section{NOTAS}

1. Ver: Bair, Steele y Mills, 2014; Boothroyd Jucker, Thornborrow, Jamieson, Burt, Barton, Evans y Tovee, 2016; Chaker, Chang y Hakim-Larson, 2015; Cocca, Ornelas, Perez y Ramírez, 2016; Fitzsimmons-Craft, Harney, Koehler, Danzi, Riddell y Bardone-Cone, 2012; Holland y Tiggemann, 2016; Magallares, 2016; Mills, Jadd y Key, 2012; Ramirez y Milan, 2016; Rice, Prichard, Tiggemann y Slater, 2016; Veldhuis, te Poel, Pepping, Konijn y Spekman, 2017; Whyte, Newman y Voss, 2016; Worobey y Worobey, 2014.

2. La traducción es de la autora.

3. La traducción es de la autora.

4. Ídem

5. La traducción es de la autora, las cursivas son del texto original.

6. Por ejemplo, Kress y van Leeuwen (1996) en su texto Reading Images presentan un extenso estudio sobre la revista Cospomopolitan. Si bien logran dar cuenta de una serie de recursos socio-semióticos presentes en la publicación, no dan cuenta del modo o el poder con esas imágenes afectan a sus lectoras/es.

7. Este proyecto de financiado por el Fondo Nacional de Desarrollo Científico y Tecnológico (FONFECYT). El proyecto está dirigido por María-Alejandra Energici.

8. Si bien se esperaba una amplia presencia de siluetas femeninas, la ausencia de siluetas masculinas no permite construir este grado de variación para caracterizar siluetas en medios de comunicación. Es por ello que en este trabajo nos limitaremos a las siluetas femeninas.

9. De hecho, piénsese en lo paradójico de vender chocolates con la imagen de una mujer extremadamente delgada.

10. Si bien se puede considerar que este tipo de silueta hace alguna referencia a cuerpos curvilíneos al estilo Beyoncé, la ausencia de este tipo de cuerpos en la publicidad y la preferencia por modelos de rasgos nórdicos no nos permiten indagar en mayor profundidad en esta tesis.

11. Material de Análisis. Libro de Connie Achurra "Cocina Sana y Feliz", publicado en 2017

12. Ídem.

13. Ídem.

14. Ídem.

15. Ídem.

16. Hickey-Moody (2013) propone que estudio de las estéticas, involucra el análisis de las afectividades, en tanto que las estéticas nos mueven, nos interpelan corporal y afectivamente. 


\section{REFERENCIAS}

AHMED, Sara. (2007). “The Happiness Turn”. New Formations, 63, pp. 7-14.

AHMED, Sara. (2017), Living a feminist life. Durham, Duke University Press.

AITSI-SELMI, Amina; BELL, Ruth; SHIPLEY, Martin J. y MARMOT, Michael G. (2014), “Education Modifies the Association of Wealth with Obesity", in Women in Middle-Income but Not Low-Income Countries: An Interaction Study Using Seven National Datasets, 20052010. PLOS ONE, vol. 9, no 3, pp. 1-10. https://doi.org/10.1371/journal.pone.0090403

BAIR, Allison, STEELE; Jennifer R. y MILLS, Jennifer S. (2014), “Do these norms make me look fat? The effect of exposure to others' body preferences on personal body ideals". Body Image, vol. 11, no 3, pp. 275-281. https:/ /doi.org/10.1016/j.bodyim.2014.04.004

BARTKY, Sandra Lee. (1998), "Foucault, Feminity and the Modernization of Patriarchal Power", in R. Weitz (Ed.), The Politics of Women's Bodies. New York,Oxford: Oxford Univesity Press, pp. $25-45$.

BONAVITTA, Paola y GARAY HERNÁNDEZ, Jimena. (2017), “De estereotipos, violencia y sexismo: la construcción de las mujeres en los medios mexicanos y argentinos". Anagramas - Rumbos y Sentidos de La Comunicación, vol. 9, no 18, pp. 15-30. https:/ /doi.org/10.22395/ angr.v9n18a1

BOOTHROYD, Lynda G.; JUCKER, Jean Luc; THORNBORROW, Tracy; JAMIESON, Mark A.; BURT, D. Michael; BARTON, Robert A.; EVANS, Elizabeth y TOVEE, M. J. (2016), “Television exposure predicts body size ideals in rural Nicaragua". British Journal of Psychology, vol. 107, no 4, pp. 752-767. https:/ / doi.org/10.1111/bjop.12184

BRAUN, Virginia y CLARKE, Victoria. (2006), "Using Thematic analysis in Psychology". Qualitative Research in Psychology, vol. 3, no 1, pp. 77-101.

BROCHU, Paula M. y ESSES, Victoria M. (2011)., "What's in a Name? The Effects of the Labels "Fat" Versus "Overweight" on Weight Bias". Journal of Applied Social Psychology, vol. 41, no 8, pp. 1981-2008. https://doi.org/10.1111/j.1559-1816.2011.00786.x

CHAKER, Zina; CHANG, Felicia M., y HAKIM-LARSON, Julie. (2015), “Body satisfaction, thin-ideal internalization, and perceived pressure to be thin among Canadian women: The role of acculturation and religiosity". Body Image, vol. 14, pp. 85-93. https://doi. org/10.1016/j.bodyim.2015.04.003

COCCA, Armando; ORNELAS, José René Blanco; PEREZ, Jesús Enrique P. y RAMÍREZ, Jesús V. (2016), "Actual, social and ideal body image in Mexican adolescents and their relation with body dissatisfaction: gender differences". Retos, vol. 30, no 2, pp. 189-192.

COLEMAN, Rebecca. (2013), Transforming images. Screens, affect, futures. Oxon, Routledge.

COLEMAN, Rebecca. (2014), "Inventive Feminist Theory: Representation, Materiality and Intensive Time". Women: A Cultural Review, vol. 25, no 1, pp. 27-45. https://doi.org/10.1080 /09574042.2014.901098

COLEMAN, Rebecca y RINGROSE, Jessica. (2013), “Introduction: Deleuze and Research Methodologies", in R. Coleman y J. Ringrose (Eds.), Deleuze and Research Methodologies. Edinburgh, Edinburgh University Press, pp. 1-22. 
COLLIPAL, Erika y GODOY, María Pía. (2015), “Representaciones Sociales de la Obesidad en Jóvenes Preuniversitarios y Universitarios Social Representations of Obesity in Pre-University and University Youth". Int. J. Morphol, vol. 33, no 3, pp. 877-882. https:/ /doi. org/10.4067/S0717-95022015000300012

COLLIPAL, Erika; SILVA, Hector; VARGAS, Ramiro y MARTÍNEZ, Cristian. (2006), "Significado de la Obesidad para los Adolescentes de Temuco-Chile". International Journal of Morphology, vol. 24, no 2, pp. 259-262.

COLLS, Rachel y EVANS, Bethan. (2014), "Making space for fat bodies?: A critical account of 'the obesogenic environment'” . Progress in Human Geography, vol. 38, no 6, pp. 733-753. https://doi.org/10.1177/0309132513500373

CUNDALL, Amelia y GUO, Kun. (2017), “Women gaze behaviour in assessing female bodies: the effects of clothing, body size, own body composition and body satisfaction". Psychological Research, vol. 81, no 1, pp. 1-12. https://doi.org/10.1007/s00426-015-0726-1

El ranking de los malls en Chile. (2012), La Segunda Online. Retrieved from http:/ /www. lasegunda.com/Noticias/Economia/2012/08/771708/el-ranking-de-los-malls-en-chileel-mas-grande-el-con-mayor-numero-de-estacionamientos-y-el-lider-en-visitas

ENERGICI, María-Alejandra. (2018), “Afectividad y subjetividad femenina: análisis de la gordura como código moral". Limite. Revista Interdisciplinaria de Filosofía y Psicología, vol. 13, no 43, pp. 17-28.

ENERGICI, María-Alejandra; ACOSTA, Elaine; BÓRQUEZ, Florencia y HUAIQUIMILLA, Macarena. (2017), “Gordura, Discriminación y Clasismo: un Estudio en Jóvenes de Santiago de Chile”. Psicologia \& Sociedade, vol. 29, pp. 1-10.

ENERGICI, María-Alejandra; ACOSTA, Elaine; HUAIQUIMILLA, Macarena y BORQUEZ, Florencia. (2016), "Feminización de la gordura: estudio cualitativo en Santiago de Chile". Revista de Psicología, vol. 25, no 2, pp. 1-17. https:/ / doi.org/http:/ / dx.doi.org/10.5354/07190581.2016.44771

FAIRCLOUGH, Norman. (2003), “El análisis crítico del discurso como método para la investigación en ciencias sociales", in R. Wodak y M. Meyer (Eds.), Método del Análisis Crítico del Discurso. Barcelona, Gedisa

FIKKAN, Janna L. y ROTHBLUM, Esther D. (2012), “Is Fat a Feminist Issue? Exploring the Gendered Nature of Weight Bias". Sex Roles, vol. 66, pp. 575-592. https:/ /doi.org/10.1007/ s11199-011-0022-5

FITZSIMMONS-CRAFT, Ellen; HARNEY, Megan B.; KOEHLER, Laura G.; DANZI, Lauren E.; RIDDELL, Margaret K. y BARDONE-CONE, Anna M. (2012), “Explaining the relation between thin ideal internalization and body dissatisfaction among college women: The roles of social comparison and body surveillance". Body Image, vol. 9, no 1, pp. 43-49. https://doi.org/10.1016/j.bodyim.2011.09.002

FOUCAULT, Michel. (2002), Historia de la sexualidad. 2 El uso de los placeres. Madrid, Siglo XXI Editores.

FRASER, Suzanne; MAHER, Jean Maree y WRIGHT, Jan. (2010), “Between bodies and collectivities: Articulating the action of emotion in obesity epidemic discourse". Social Theory $\mathcal{E}$ Health, vol. 8, no 2, pp. 192-209. https:/ /doi.org/10.1057/sth.2009.28 
FROST, Samanthaa. (2011), "The Implications of the New Materialism for Feminist Epistemology", inH. E. Grasswick (Ed.), Feminist Epistemology and Philosophy of Science: Power in Knowledge. Amsterdam, Springer Netherlands, pp. 69-83. https://doi. org/10.1002/9780470696132.ch13

GARCÍA-MUÑOZ, Nuria y MARTÍNEZ-GARCÍA, Luisa del Carmen. (2009), “The positive representation of the image of women in the media". Comunicar, vol. 16, no 32, pp. 209-214. https://doi.org/10.3916/c32-2009-03-002

GIACOMAN, Claudia. (2010), “La corpulencia como un hecho social entre los adultos chilenos del siglo XXI". Caderno Espaço Feminino, vol. 23, pp. 221-236.

GÓMEZ-ESCALONILLA, Gloria; GARCÍA, Antonio; SANTÍN, Marina; RODRÍGUEZ, Raquel y TORREGROSA, Juanå. (2008), “La imagen de la mujer política en los medios de comunicación". Feminismo/S, vol. 11, pp. 59-71.

GROSZ, Elizabeth. (1994), Volatile Bodies. Toward a corporeal feminism. Bloomington, Indiana University Press.

HALSE, Christine. (2009), "Bio-Citizenship. Virtue discourse and the Birth of the Bio-Citizen", in J. Wright y V. Harwood (Eds.), Biopolitics and the "Obesity Epidemic". Governing bodies. Nueva York y Oxon, Routledge, pp. 45-59.

HARWOOD, Valerie. (2009), "Theorizing Biopedagogies", in J. Wright y V. Harwood (Eds.), Biopolitics and the "Obesity Epidemic". Governing bodies. Nueva York y Oxon, Routledge, pp. 15-30.

HICKEY-MOODY, Ana. (2013), "Affect as Method: Feelings, Aesthetics and Affective Pedagogy", inR. Coleman y J. Ringrose (Eds.), Deleuze and Research Methodologies. Edinburgh, Edinburgh University Press, pp. 79-95.

HOLLAND, Grace y TIGGEMANN, Marika. (2016), "Strong beats skinny every time": Disordered eating and compulsive exercise in women who post fitspiration on Instagram. International Journal of Eating Disorders, vol. 50, no 1, pp. 76-79. https://doi.org/10.1002/ eat.22559

JACKSON, Alecia Y. y MAZZEI, Lisa A. (2018), “Thinking with Theory. ANew Analytic for Qualitative Inquiry", in N. Denzin y Y. Lincoln (Eds.), The Sage Handbook of Qualitative Research. Thousand Oaks, Sage Publications, pp. 716-737. https://doi.org/10.4324/9781351044998-13

JUTEL, Annemarie. (2009), “Doctor's Orders. Diagnosis, Medical Authority and the Exploitation of the Fat Body", in J. Wright y V. Harwood (Eds.), Biopolitics and the "Obesity Epidemic". Governing bodies. Nueva York y Oxon, Routledge, pp. 60-77.

KARK, Malin y KARNEHED, Nina. (2012), “Weight status at age 18 influences marriage prospects. A population-based study of Swedish men". BMC Public Health, vol. 12, no 1, pp. 833-839. Retrieved from http://10.0.4.162/1471-2458-12-833

KRESS, Gunther y VAN LEEUWEN, Theo. (1996), Reading images. Oxon, Routledge.

KWAN, Samantha y TRAUTNER, Mary Nell. (2009), “Beauty work: individual and institutional rewards, the reproduction of gender, and questions of agency". Sociology Compass, vol. 3, no 6, pp. 1017-1021. https:/ /doi.org/10.1111/j.1751-9020.2009.00243.x 
LATOUR, Bruno. (2008), Reensamblar lo social: una introducción a la tería del actor red. Buenos Aires, Ediciones Manantial.

LE BRETON, David. (2002), La sociología del cuerpo. Buenos Aires, Nueva Visión.

LORBER, Judith y MARTIN, Patricia Y. (2013), “The Socially Constructed Body: Insights from Feminist Theory", in Illuminating Social Life: Classical and Contemporary Theory Revisited. Thousand Oaks, Sage Publications Inc.

LUPTON, Deborah. (2013), Fat. Nueva York, Routledge.

MAGALLARES, Alejandro. (2016), "Eating concerns, body dissatisfaction, thinness internalization and antifat attitudes and their relationship with gender ideology in a sample of men". Preocupación Por La Comida, Insatisfacción Corporal, Interiorización de La Delgadez y Actitudes Antiobesos En Su Relación Con Las Ideologías de Género En Una Muestra de Hombres., vol. 32, no 1, pp. 167-173. Retrieved from http://10.0.23.130/analesps.32.1.182651

MART, Luisa. (2009), La representación positiva de la imagen de las mujeres en los medios, 1-4. https: / /doi.org/10.3916/c32-2009-03-002

MASON, Katherine. (2012), “The Unequal Weight of Discrimination : Gender , Body Size , and Income Inequality". Social Problems, vol. 59, no 3, pp. 411-435. https:/ /doi.org/10.1525/ sp.2012.59.3.411.

Metro revela cuáles son las estaciones con mayor afluencia anual de pasajeros. (2017), Meganoticias. Retrieved from https:/ / www.mega.cl/noticias/nacional/202109-metro-revela-cuales-son-las-estaciones-con-mayor-afluencia-anual-de-pasajeros.html

MILLS, Jennifer S.; JADD, Rachel y KEY, Brenda L. (2012), “Wanting a body that's better than average: The effect of manipulated body norms on ideal body size perception". Body Image, vol. 9, no 3, pp. 365-372. https://doi.org/10.1016/j.bodyim.2012.03.004

O'BRIEN, Kerry S.; Latner, Janet D.; EBNETER, Daria y HUNTER, Jackie A. (2013), “Obesity discriminatio: the role of physical appearance, personal ideology and anti-fat prejudice". International Journal of Obesity, vol. 37, no 3, pp. 455-460. https:/ / doi.org/10.1007/s00426015-0726-1

PARKER, Ian. (1996), “Discurso, cultura y poder en la vida cotidiana”, inA. J. Gordo y J. L. Linaza (Eds.), Psicologías, discursos y poder (PDP). Madrid, Visor, pp. 79-92.

RAMIREZ, Jenna C. y MILAN, Stephanie. (2016), "Perceived size of friends and weight evaluation among low-income adolescents". Journal of Behavioral Medicine, vol. 39, no 2, pp. 334-345. https: / / doi.org/10.1007/s10865-015-9682-x

RENOLD, Emma y MELLOR, David. (2013), "Deleuze and Guattari in the Nursery: Towards an Etnographic Multi-Sensory Mapping of Gendered Bodies and Becomings", in R. Coleman y J. Ringrose (Eds.), Deleuze and Research Methodologies. Edinburg, Edinburgh University Press, pp. 23-41.

RICE, Karlie, PRICHARD, Ivanka; TIGGEMANN, Marika y SLATER, Amy. (2016), “Exposure to Barbie: Effects on thin-ideal internalisation, body esteem, and body dissatisfaction among young girls". Body Image, vol. 19, pp. 142-149. https://doi.org/10.1016/j. bodyim.2016.09.005 
RISCADO, Caio A. (2019), “Gordura que não sai : análise dos discursos de ódio nas redes a partir da interação com imagens da performance g ordura trans \# 3 / gordura". Periodicus, vol. 1, no 10, pp. 131-162.

ROTHBLUM, Esther D. (2011), "Fat Studies", inj. Cawley (Ed.), The Oxford Handbook of Social Science of Obesity. Oxford, Oxford Univesity Press, pp. 173-183.

SHILLING, Chris. (2012), The Body and Social Theory (3º. London, Sage Publications.

SILVAARAÚJO, Lidiane; DE LIMA COUTINHO, Maria da Penha; PEREIRAALBERTO, Maria de Fátima; DIAS SANTOS, Anderson Mathias y DE LIMA PINTO, Adriele Vieira. (2013), "Weight-based discrimination: social representations of internet users about fat phobia". Psicologia Em Estudo, vol. 23, pp. 1-17. https://doi.org/10.4025/psicolestud.v23.e34502

SMAILES, Sophie. (2014), "Negotiating and Navigating my Fat Body - Feminist Autoethnographic Encounters". Athenea Digital, vol. 14, no 4, pp. 49-61.

SOBAL, Jeffery. (2011), "The sociology of obesity”, in J. Crawley (Ed.), The Oxford Handbook of Social Science of Obesity. Oxford, Oxford Univesity Press, pp. 105-119.

SOLOVAY, Sondra y ROTHBLUM, Esther D. (2009), "Introduction”, in E. Rothblum y S. Solovay (Eds.), The Fat Studies Reader. Nueva York, New York University Press, pp. 1-7.

TIAINEN, Milla; KONTTURI, Katve-Kaisa y HONGISTO, Ilona. (2015), “Framing, Following, Middling: Towards Methodologies of Relational Materialities". Cultural Studies Review, vol. 2, no 12 , pp. 14-46.

TISCHNER, Irmgard. (2013), Fat Lives. Nueva York, Routledge.

ULIAN, Mariana Dimitrov; GUALANO, Bruno; BENATTI, Fabiana B.; DE CAMPOS-FERRAZ, Patricia L.; ROBLE, Odilon; MODESTO, Bruno T.; DE MEDEIROS, Gabriel; UNSAIN, Ramiro; DE MOIRAS SATO, Priscilla; MACHADO, Ana Carolina y SCAGLIUSI, Fernanda B. (2016), "Eu Tenho Um Corpo Gordo, E Agora? Relatos De Mulheres Obesas Que Participaram De Uma Intervenção Não Prescritiva, Multidisciplinar E Baseada Na Abordagem "Health At Every Size®."”. DEMETRA: Alimentação, Nutrição \& Saúde, vol. 11, no 3, pp. 697-722. https:/ /doi.org/10.12957/demetra.2016.22501

URIBE, Rodrigo; MANZUR, Enrique; HIDALGO, Pedro y FERNÁNDEZ, Rebeca. (2008), "Estereotipos de género en la publicidad: un análisis de contenido de las revistas chilenas". Academia. Revista Latinoamericana de Adminsitración, vol. 41, pp. 1-18.

VARTANIAN, Lenny R., y SMYTH, Joshua M. (2013), “Primum Non Nocere: Obesity Stigma and Public Health". Journal of Bioethical Inquiry, vol. 10, no 1. https://doi.org/10.1007/ s11673-012-9412-9

VELDHUIS, Jolanda; TE POEL, Fam; PEPPING, Rian; KONIJN, Elly A. y SPEKMAN, Marloes L. C. (2017), "Skinny is prettier and normal: I want to be normal"-Perceived body image of non-Western ethnic minority children in the Netherlands. Body Image, vol. 20, pp. 74-86. https:/ /doi.org/10.1016/j.bodyim.2016.11.006

WANN, Marilyn. (2009), "Foreward: Fat Studies: An Invitation to Revolution”, in E. Rothblum y S. Solovay (Eds.), The Fat Studies Reader. Nueva York, New York University Press, pp. xi--xxv. 
María-Alejandra Energici

WHYTE, Cavel; NEWMAN, Leonard S. y VOSS, David. (2016), “A Confound-Free Test of the Effects of Thin-Ideal Media Images on Body Satisfaction". Journal of Social and Clinical Psychology, vol. 35, no 10, pp. 822-839. https://doi.org/10.1521/jscp.2016.35.10.822

WOROBEY, John y WOROBEY, Harriet S. (2014), “Body-size stigmatization by preschool girls: In a doll's world, it is good to be "Barbie."'. Body Image, vol. 11, no 2, pp. 171-174. https://doi.org/10.1016/j.bodyim.2013.12.001

WRIGHT, Jan (2009). "Biopower, Biopedagogies and the Obesity Epidemic", in J. Wright y V. Harwood (Eds.), Biopolitics and the "Obesity Epidemic". Governing bodies. Nueva York y Oxon, Routledge, pp. 1-14.

WRIGHT, Jan y HARWOOD, Valerie (Eds.). (2009), Biopolitics and the "Obesity Epidemic". Governing Bodies. Nueva York y Oxon, Routledge. 


\section{RESUMO}

Silhuetas Femininas na Mídia: Estéticas para a Subjetivação

O objetivo deste trabalho é descrever as avaliações, significados e ações típicas atribuídas às diferentes silhuetas ou volumes corporais nos meios de comunicação em Santiago do Chile. A sociologia anglo-saxônica tem documentado a discriminação sofrida pelas pessoas gordas, assumindo que as silhuetas finas são a contraparte ideal. A identificação desta forma de violência não tem sido acompanhada de modelos explicativos. O estudo aqui apresentado foi de natureza qualitativa. Em um corpo de 336 imagens coletadas, com uma baixa variabilidade em que 85\% apresentam silhuetas ideais, foi realizada uma análise difratária em 13 imagens de revistas e anúncios publicitários. Os resultados descrevem quatro tipos de silhuetas com seus respectivos significados, avaliações e ações. Conclui-se que as imagens prescrevem ideais sociais que envolvem certos tipos de corporeidades, bem como certas estéticas com as quais estas ações devem ser realizadas.

Palavras-chave: Corpo; Afetividade; Imagens; Gordura; Magreza

\section{ABSTRACT \\ Women's Silhouettes in the Media: Aesthetics for Subjectivation}

This work aims to describe the typical evaluations, meanings and actions that are attributed to the various silhouettes or body volumes in the media in Santiago de Chile. From Anglo-Saxon sociology the discrimination suffered by fat people has been documented, assuming that thin silhouettes are the ideal counterpart. The identification of this form of violence has not been accompanied by explanatory models. The study presented was of a qualitative nature. On a body of 336 images collected, with little variability while $85 \%$ present ideal silhouettes, a diffractive analysis was analyzed on 13 images from magazines and advertisements. The results describe four types of silhouettes with their respective meanings, valuations and actions. It is concluded that in the images social ideals are prescribed that involve certain types of corporalities, as well as certain aesthetics with which these actions must be carried out.

Keywords: Body; Affectivity; Images; Fatness; Thinness 


\section{RÉSUMÉ \\ Silhouettes Féminines dans les Médias de Communication: l'Esthétique pour la Subjectivité}

Le but de ce travail est de décrire les évaluations, les significations et les actions typiques attribuées aux différentes silhouettes ou volumes corporels dans les médias de communication à Santiago du Chili. La société anglaise a documenté la discrimination dont souffrent les personnes grasses, en supposant que les silhouettes minces sont la contrepartie idéale. L'identification de cette forme de violence n'a pas été accompagnée de modèles explicatifs. L'étude qui se présente était de caractère qualitatif. Sur un corpus de 336 images collectées, avec une faible variabilité, pour que $85 \%$ présentent des silhouettes idéales, une analyse diffractante a été analysée sur 13 images de magazines et de publicités. Les résultats décrivent quatre types de silhouettes avec leurs significations, évaluations et actions respectives. On en conclut que dans les images sont prescrits des idéaux sociaux qui impliquent certains types de corporéités, ainsi que des connaissances esthétiques avec lesquelles ces actions doivent être menées.

Mots-clés: Corps; Affectivité; Images; Graisse; Minceur

\section{RESUMEN}

Siluetas Femeninas en Medios de Comunicación: Estéticas para la Subjetivación

El objetivo de este trabajo es describir las valoraciones, significados y acciones típicas que se atribuyen a las diversas siluetas o volúmenes corporales en los medios de comunicación en Santiago de Chile. Desde la sociología anglosajona se ha documentado la discriminación que sufren las personas gordas, asumiéndose que las siluetas delgadas son la contraparte ideal. La identificación de esta forma de violencia no ha ido acompañada de modelos explicativos. El estudio que se presenta fue de carácter cualitativo. Sobre un cuerpo de 336 imágenes recolectadas, con una escasa variabilidad en tanto que el $85 \%$ presenta siluetas ideales, se analizó un análisis difractario sobre 13 imágenes de revistas y publicidades. En los resultados se describen cuatro tipos de siluetas con sus respectivos significados, valoraciones y acciones. Se concluye que en las imágenes se prescriben ideales sociales que involucran ciertos tipos de corporalidades, así como también ciertas estéticas con la que estas acciones deben llevarse a cabo.

Palabras clave: Cuerpo; Afectividad; Imágenes; Gordura; Delgadez 